\title{
Conductive polymer-based nanoparticles for laser-mediated photothermal ablation of cancer: synthesis, characterization, and in vitro evaluation
}

This article was published in the following Dove Press journal:

International Journal of Nanomedicine

16 January 2017

Number of times this article has been viewed

Travis Cantu,' Kyle Walsh, ${ }^{2}$ Varun P Pattani, ${ }^{3}$ Austin J Moy, ${ }^{3}$ James W Tunnell, ${ }^{3}$ Jennifer A Irvin, ${ }^{1,2}$ Tania Betancourt ${ }^{1,2}$

'Materials Science, Engineering, and Commercialization Program, Texas State University, San Marcos, TX, USA; ${ }^{2}$ Department of Chemistry and Biochemistry, Texas State University, San Marcos, TX, USA; ${ }^{3}$ Department of Biomedical Engineering, The University of Texas at Austin, Austin, TX, USA

Video abstract

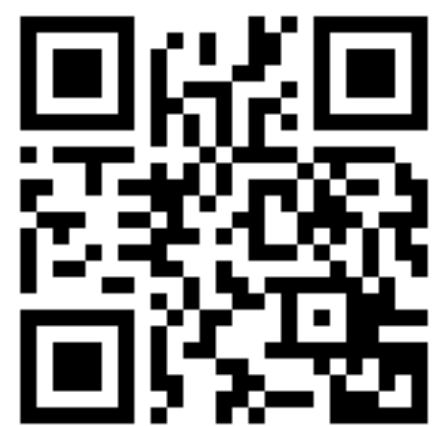

Point your SmartPhone at the code above. If you have a QR code reader the video abstract will appear. Or use:

Correspondence: Tania Betancourt Department of Chemistry and Biochemistry, Texas State University, 601 University Drive, San Marcos,

TX 78666, USA

Tel + I 5I 22457703

Fax + I 5122452374

Email tb26@txstate.edu
https://youtu.be/4bHwCIR9Dg/

Abstract: Laser-mediated photothermal ablation of cancer cells aided by photothermal agents is a promising strategy for localized, externally controlled cancer treatment. We report the synthesis, characterization, and in vitro evaluation of conductive polymeric nanoparticles (CPNPs) of poly(diethyl-4,4'-\{[2,5-bis(2,3-dihydrothieno[3,4-b][1,4]dioxin-5-yl)-1,4-phenylene ] bis(oxy) $\}$ dibutanoate) (P1) and poly(3,4-ethylenedioxythiophene) (PEDOT) stabilized with 4-dodecylbenzenesulfonic acid and poly(4-styrenesulfonic acid-co-maleic acid) as photothermal ablation agents. The nanoparticles were prepared by oxidative-emulsion polymerization, yielding stable aqueous suspensions of spherical particles of $<100 \mathrm{~nm}$ diameter as determined by dynamic light scattering and electron microscopy. Both types of nanoparticles show strong absorption of light in the near infrared region, with absorption peaks at $780 \mathrm{~nm}$ for P1 and $750 \mathrm{~nm}$ for PEDOT, as well as high photothermal conversion efficiencies ( $50 \%)$, that is higher than commercially available gold-based photothermal ablation agents. The nanoparticles show significant photostability as determined by their ability to achieve consistent temperatures and to maintain their morphology upon repeated cycles of laser irradiation. In vitro studies in MDA-MB-231 breast cancer cells demonstrate the cytocompatibility of the CPNPs and their ability to mediate complete cancer cell ablation upon irradiation with an 808-nm laser, thereby establishing the potential of these systems as agents for laser-induced photothermal therapy.

Keywords: conductive polymers, nanoparticles, breast cancer, emulsion polymerization, nanomedicine, photothermal ablation, PEDOT, photothermal conversion efficiency, MDA-MB-231

\section{Background}

It is predicted that there will be nearly 1.7 million newly diagnosed cancer patients this year. ${ }^{1}$ With many of these patients, treatment options will include radiation and chemotherapy. ${ }^{1}$ While effective, these treatments are invasive and have severe side effects. ${ }^{2,3}$ With the constant effort to improve the patient's quality of life, researchers have searched for alternative methods that are highly selective and that can provide more effective treatment against this malignant disease. Hyperthermia is a treatment method in which the body is exposed to elevated temperatures (often $\geq 45^{\circ} \mathrm{C}$ ) locally or regionally., ${ }^{4,5}$ At these elevated temperatures, cells will either be killed or severely damaged, allowing for radiation and chemotherapy to be more effective at lower doses. ${ }^{6}$ While the idea of using heat to treat cancer and other illnesses is far from new - hyperthermia treatments can be dated back to the ancient Egyptian era ${ }^{6}-$ advances in optics, biotechnology, nanomaterials, and medicine have all contributed to the reality of using thermal therapy as a viable option. Several different methods have been used to achieve thermal therapy, the most common method to date being hy
hereby accept the Terms. Non-commercial uses of the work are permitted without any further permission from Dove Medical Press Limited, provided the work is properly attributed. For permission for commercial use of this work, please see paragraphs 4.2 and 5 of our Terms (https://www.dovepress.com/terms.php). 
radiofrequency ablation. ${ }^{7}$ More recently, the use of light as a stimulus for thermal therapy or photothermal therapy (PTT) has become widely studied. The nature of PTT therapy allows for a less invasive, highly selective treatment that has shown to be highly effective in the ablation of cancerous cells. PTT therapy is a method where light is used to excite PTT agents, which in turn release energy as heat. ${ }^{6}$

PTT therapy typically utilizes near infrared (NIR) light as a source of energy to excite PTT agents. Light has a higher penetration depth in the NIR optical window between 700 and $900 \mathrm{~nm}$, where human tissue has minimal absorption, scattering, and fluorescence. ${ }^{8}$ A vast majority of the research in this field has focused on the use of gold nanoparticles (GNPs), including gold nanorods (GNRs) ${ }^{9}$ and gold nanoshells (GNSs), ${ }^{10,11}$ as well as the use of carbon-based materials, including conductive polymers, ${ }^{12-15}$ graphene oxide, ${ }^{16}$ and single- and multiwalled carbon nanotubes ${ }^{17,18}$ as PTT agents. While the potential of GNPs has been demonstrated in several instances and their development has reached the level of phase 1 clinical trials, the effectiveness and safety of carbon-based PTT agents have not been fully investigated.

Organic conductive polymer nanoparticles (CPNPs) have gained the attention of many researchers in recent years. Due to their unique structure, these polymers have the ability to be finely tuned to absorb light in the NIR region of the spectrum. This can be achieved by modifying the backbone of the polymer chain, incorporating pendant groups along the backbone of the polymer chain, or creating blends of polymers with different characteristics. ${ }^{19}$ Also, the polymer chains can be modified to enable the conjugation of biomarkers or other biomolecules directly onto the backbone.

While conductive polymers have been studied extensively in electronics, only a handful of these polymers have been investigated as PTT agents. One reason for this is the inability of these polymers to dissolve in aqueous solutions. Oxidative-emulsion polymerization is one method that can be used to overcome this limitation. In this work, we demonstrate the preparation of two types of low oxidation potential CPNPs based on poly(diethyl-4,4' $-\{[2,5$-bis $(2,3-$ dihydrothieno[3,4-b][1,4]dioxin-5-yl)-1,4-phenylene] bis(oxy) $\}$ dibutanoate) (P1) and poly(3,4-ethylenedioxythiophene) (PEDOT) stabilized with 4-dodecylbenzenesulfonic acid (DBSA) and poly(4-styrenesulfonic acid-co-maleic acid) (PSS-co-MA) via oxidative-emulsion polymerization and their evaluation as PTT agents. The effect of chemical structure of the two polymers on the absorption properties of the NPs and, thereby, on their effectiveness as agents for photothermal ablation was studied. We investigated the PTT conversion efficiencies of both types of CPNPs and compared them to those of commercially available CPNPs (Clevios PH1000), GNRs, and GNSs. To the best of our knowledge, this is the first report of the comparison of the PTT conversion efficiencies of CPNPs to those of gold-based PTT agents. In vitro investigation of the cytocompatibility and ablative capabilities of these CPNPs in MDA-MB-231 breast cancer cells showed the potential of these systems as agents for laser-induced PTT therapy.

\section{Materials and methods Materials}

3,4-Ethylenedioxythiophene (EDOT) was purchased from Sigma-Aldrich (St Louis, MO, USA). DBSA was purchased from TCI America (Portland, OR, USA). One hundred kilo Dalton molecular weight cutoff cellulose ester membranes were obtained from Spectrum Laboratories (Rancho Dominguez, CA, USA). Clevios PH1000 was obtained from Heraeus GmbH (Yardley, PA, USA), Conductive Polymer Division. PEGylated GNRs were graciously provided by NanoHybrids, Inc. (Austin, TX, USA); these GNRs had a longitudinal peak at $807 \mathrm{~nm}$, a width of $11.4 \pm 1.3 \mathrm{~nm}$, a length of $47 \pm 3.2 \mathrm{~nm}$, and an aspect ratio of 1:4.15. PEGylated GNSs were graciously provided by Nanospectra Biosciences, Inc. (Houston, TX, USA). These GNSs had peak optical density (OD) at $792 \mathrm{~nm}$. The live/dead viability assay for mammalian cells was obtained from Thermo Fisher Scientific (Austin, TX, USA).

\section{Monomer synthesis}

Diethyl-4,4' $-\{[2,5$-bis(2,3-dihydrothieno[3,4-b][1,4]dioxin5-yl)-1,4-phenylene]bis(oxy)\} dibutanoate) (M1) (Figure 1) was synthesized as previously reported by Cantu et al. ${ }^{20}$ EDOT was purified as described previously. ${ }^{21}$ EDOT was first lithiated at $-78^{\circ} \mathrm{C}$, followed by transmetallation with $\mathrm{ZnCl}_{2}$ at $0^{\circ} \mathrm{C}$. EDOT- $\mathrm{ZnCl}$ was then coupled to the precursor diethyl 4,4'-[(2,5-dibromo-1,4-phenylene)bis(oxy)]dibutanoate by Negishi coupling and refluxed for 4 days. The product was collected by extracting the organic layer and washing several times with water, dried over $\mathrm{MgSO}_{4}$, filtered, and further dried under reduced pressure yielding M1. The dried product was recrystallized in 1:1 benzene:ethyl acetate solution and filtered. The collected crystals were stored at $4^{\circ} \mathrm{C}$ under argon until further use. The structure of M1 was confirmed by ${ }^{1} \mathrm{H}$ and ${ }^{13} \mathrm{C}$ nuclear magnetic resonance spectroscopy.

\section{NP preparation}

NPs were prepared from M1 or EDOT using a two-surfactant emulsion polymerization method (Figure 1A), similar to 


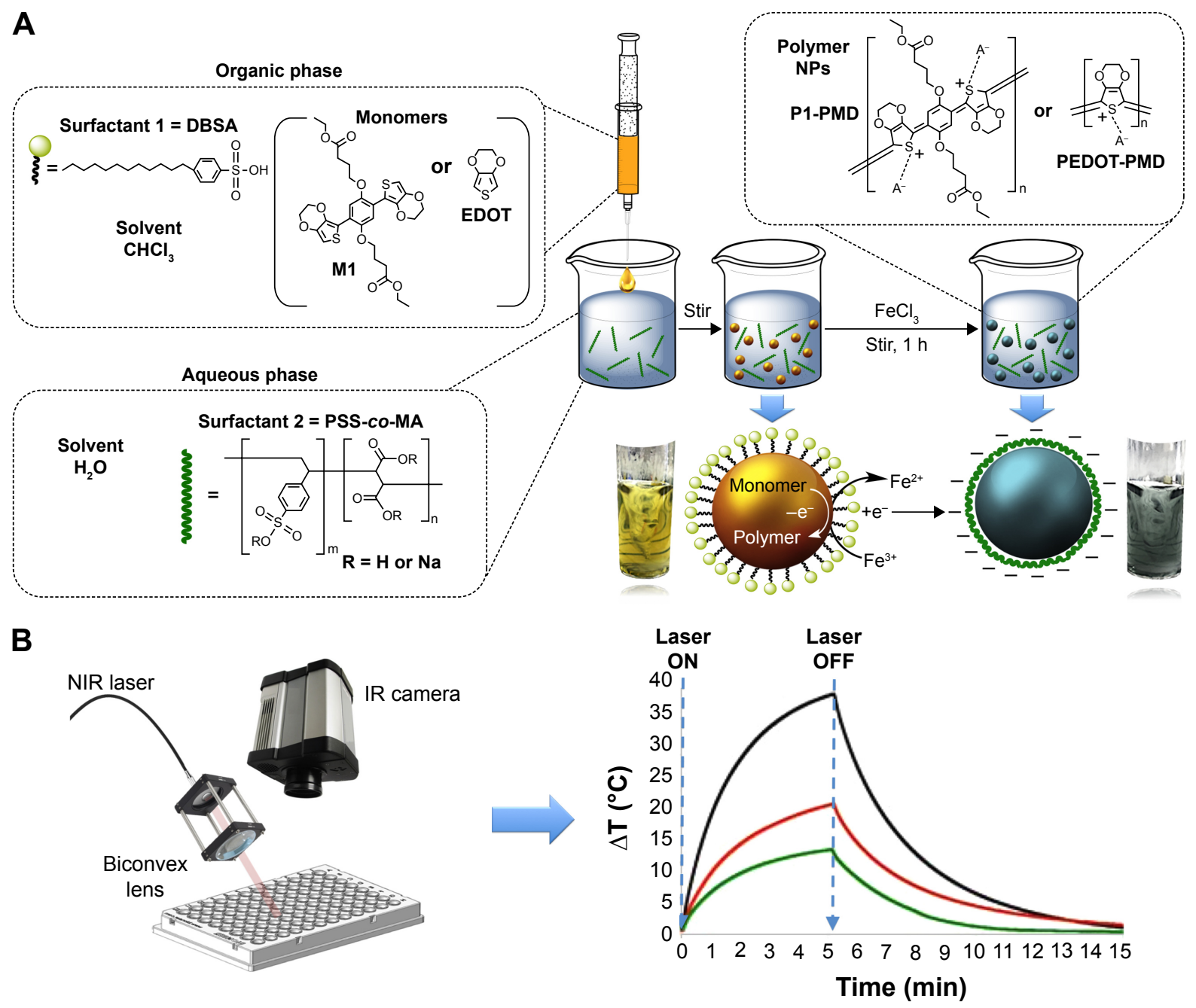

Figure I Nanoparticle preparation and evaluation.

Notes: (A) Process used for NP preparation via oxidative-emulsion polymerization. (B) Setup utilized for PTT studies. The laser beam transported through an optical fiber was focused through a biconvex lens set a slight angle so as to not to interfere with temperature $(T)$ measurements. A thermal IR camera was placed directly above the sample well to measure sample temperature changes over time.

Abbreviations: DBSA, 4-dodecylbenzenesulfonic acid; EDOT, 3,4-ethylenedioxythiophene; IR, infrared; NIR, near infrared; NPs, nanoparticles; PEDOT, poly(3,4ethylenedioxythiophene); PSS-co-MA, poly(4-styrenesulfonic acid-co-maleic acid); PTT, photothermal therapy; PI, poly(diethyl-4,4'-\{[2,5-bis(2,3-dihydrothieno[3,4-b][1,4] dioxin-5-yl)-I,4-phenylene]bis(oxy)\} dibutanoate); PI-PMD, PI:PSS-co-MA:DBSA; PEDOT-PMD, PEDOT:PSS-co-MA:DBSA.

that reported by Han et $\mathrm{al}^{22}$ and Cantu et al. ${ }^{20}$ Briefly, the monomer (M1 or EDOT) and DBSA were dissolved in $100 \mu \mathrm{L}$ of chloroform at concentrations of $16 \mathrm{mg} / \mathrm{mL}$ and $0.3 \mathrm{~g} / \mathrm{mL}$, respectively. The solution was mixed for $30 \mathrm{~min}$ to ensure homogeneity. In a separate container, PSS-co-MA sodium salt (20,000 Da, 3:1 styrenesulfonic acid:maleic acid; Sigma-Aldrich) was dissolved in $1 \mathrm{~mL}$ of ultrapure water at a concentration of $2 \% \mathrm{w} / \mathrm{v}$ and stirred for $30 \mathrm{~min}$. The organic phase was then added dropwise at $10 \mu \mathrm{L}$ intervals to the aqueous phase while stirring. The emulsion was then diluted with $3 \mathrm{~mL}$ of ultrapure water while stirring. Finally, $\mathrm{FeCl}_{3}(2.2 \mathrm{~mol})$ was added to the emulsion as an aqueous solution at $100 \mathrm{mg} / \mathrm{mL}(3.8 \mu \mathrm{L})$ and the emulsion was stirred for $1 \mathrm{~h}$ to enable the polymerization to take place. The suspension was then dialyzed for $24 \mathrm{~h}$ using a $100-\mathrm{kDa}$ molecular weight cutoff cellulose ester membrane yielding NPs of poly(diethyl-4,4'-\{[2,5-bis(2,3dihydrothieno[3,4-b][1,4]dioxin-5-yl)-1,4-phenylene] bis(oxy) $\}$ dibutanoate) (P1):PSS-co-MA:DBSA (P1-PMD) and PEDOT:PSS-co-MA-DBSA (PEDOT-PMD). The NP suspension was then stored under argon and sealed until further use. The concentration of NPs in suspension was determined by weighing the dry mass of $1 \mathrm{~mL}$ of lyophilized product.

\section{NP characterization}

Ultraviolet-visible-NIR measurements were performed using a Biotek Synergy H4 Hybrid Multi-Mode Microplate Reader. Scanning electron microscopy (SEM) samples were prepared by drop casting the NP suspension onto Si wafer, which were then coated with a 2-nm thick iridium layer using an EMS150T ES sputter coater. The samples 
were then imaged using an FEI Helios NanoLab 400 SEM at a working distance of $5 \mathrm{~mm}$ and at $5 \mathrm{kV}$. Transmission electron microscopy (TEM) samples were prepared by drop casting the NP suspension onto carbon-coated copper grids. The grid was then stained with $2 \%$ uranyl acetate solution for $3 \mathrm{~min}$. The grids were imaged using a JEOL JEM 1200 EXII TEM. The size and zeta potential of NPs in suspension were determined by dynamic light scattering (DLS) and electrophoretic mobility, respectively, using a Malvern Zetasizer Nano ZS instrument.

\section{Effect of NP concentration on laser- induced PTT activity}

The setup used for the photothermal studies is shown in Figure 1B. This setup has been previously utilized for the investigation of the photothermal conversion efficiency of gold nanostructures by Pattani et al. ${ }^{23}$ An 808-nm laser diode (RLCO-808-1000G, 9 mm; Roithner Lasertechnik $\mathrm{GmbH}$, Wien, Austria) rated at $1 \mathrm{~W}$ of power was used in these studies. An indium antimonide infrared (IR) camera (FLIR Systems, Inc., Wilsonville, OR, USA) was used to measure the temperature change of the samples. The laser was focused on a 6-mm diameter with the use of a biconvex lens (Thorlabs, Inc., Newton, NJ, USA), which was mounted at $\sim 30^{\circ} \mathrm{C}$ in order to avoid interference with the measurements of the IR camera. The samples were irradiated at a laser power of $0.56 \mathrm{~W}\left(2.0 \mathrm{~W} / \mathrm{cm}^{2}\right)$. All of the measurements were conducted in 96-well plates with a sample volume of $100 \mu \mathrm{L}$.

\section{PTT conversion efficiency of NPs}

The PTT conversion or transduction efficiency, $\eta_{T}$, of the polymeric NPs was calculated using a method previously reported by Roper et al. ${ }^{23-25} \eta_{T}$ is defined by Equation 1:

$$
\eta_{T}=\frac{Q_{\text {in,NP }}}{I_{a b s}}
$$

where $Q_{i n, N P}$ is the heat input to the solution by irradiated NPs and $I_{a b s}$ is the portion of the laser energy absorbed by the NPs. Thus, $\eta_{T}$ represents the fraction of the light absorbed by the NPs that is emitted in the form of heat.

$I_{a b s}$ can be calculated from Equation 2:

$$
O D=\log _{10}\left(\frac{I_{o}}{I_{t}}\right)=\log _{10}\left(\frac{I_{o}}{I_{o}-I_{a b s}}\right)
$$

where $O D$ is the optical density of the sample, $I_{o}$ is the incident laser intensity, and $I_{t}$ is the laser intensity transmitted through the NP suspension. Rearranging:

$$
I_{a b s}=I_{o}\left(1-10^{-O D}\right)
$$

In order to determine the energy input into the solution by the irradiated NPs $\left(Q_{i n, N P}\right)$, the total energy balance of the system is considered and shown in Equation 4:

$$
\sum_{i} m_{i} C_{p, i} \frac{d T}{d t}=Q_{\text {in,NP }}+Q_{\text {in,Samplecell }}-Q_{\text {out }}
$$

where $m_{i}$ is the mass, $C_{p, i}$ is the heat capacity, $T$ is the temperature of the sample, and $t$ is the time. It should be noted that $Q_{i n, N P}$ excludes the heat generated by the water and sample well in which the NPs are suspended during laser irradiation. The term $Q_{i n \text {,Sample } \text { ell }}$ is representative of the heat generated by the laser light absorbed by the 96 -well plate (sample well) and water. The term $Q_{\text {out }}$ is the heat transfer between the sample and the surroundings.

At steady state, the left term of Equation 4 is equal to zero. Thus, this equation reduces to:

$$
Q_{\text {in,NP }}=Q_{\text {out }}-Q_{\text {in,SampleCell }}
$$

The term $Q_{\text {out }}$ can be defined by Newton's law of cooling:

$$
Q_{\text {out }}=h A\left(T_{\text {sample, } \max }-T_{\text {amb }}\right)
$$

where $h$ is the heat transfer coefficient, $A$ is the area of the sample well, $T_{\text {sample,max }}$ is the temperature of the sample after reaching steady state during laser irradiation, and $T_{a m b}$ is the room temperature.

The value of $h A$ can be determined by measuring the cooling rate of the sample after heating to steady state and turning the laser off. In the absence of laser irradiation, the values for $Q_{i n, N P}$ and $Q_{i n, \text { Samplewell }}$ are zero and Equation 4 reduces to:

$$
\sum_{i} m_{i} C_{p, i} \frac{d T}{d t}=-E_{\text {out }}=-h A\left(T_{\text {sample } \max }-T_{\text {amb }}\right)
$$

After integrating and solving for $t$, Equation 11 becomes:

$$
t=-\frac{\sum_{i} m_{i} C_{p, i}}{h A} \ln \left(T_{\text {sample } \max }-T_{\text {amb }}\right)=-\frac{\sum_{i} m_{i} C_{p, i}}{h A} \ln (\Delta \mathrm{T})
$$


By plotting $\ln (\Delta \mathrm{T})$ vs time of the cooling, a line is obtained where the slope is equal to $\left(-\sum_{i} m_{i} C_{p, i} / h A\right)^{-1}$. The value of $h A$ can then be determined from this slope. In our experiments, $m_{i}$ and $C_{p, i}$ are the mass and heat capacity of the sample, which were approximated to those of $100 \mu \mathrm{L}$ of water.

The term $Q_{i n \text {,Samplecell }}$ was measured by irradiating a sample well containing $100 \mu \mathrm{L}$ of water using the same conditions for the irradiation of NP suspensions and is defined as:

$$
Q_{i n, \text { Samplecell }}=h A\left(T_{\text {water, } \max }-T_{\text {amb }}\right)
$$

where $h A$ is the value calculated above.

Plugging Equations 6 and 13 into Equation 5, $Q_{i n, N P S}$ can be calculated as:

$$
Q_{i n, N P}=h A\left(T_{\text {sample, } \max }-T_{a m b}\right)-h A\left(T_{\text {buffer }, \text { max }}-T_{a m b}\right)
$$

Inserting Equations 3 and 14 into Equation 1 gives:

$$
\eta_{T}=\frac{h A\left(T_{\text {sample, } \max }-T_{\text {amb }}\right)-h A\left(T_{b u f f e r, \max }-T_{a m b}\right)}{I_{o}\left(1-10^{-O D}\right)}
$$

Using Equation 11, the $\eta_{T}$ of P1-PMD and PEDOT-PMD was compared to that of commercially available CPNPs (Clevios PH1000), as well as GNRs and GNSs. For this purpose, all NP suspensions were diluted in water to an OD of 0.25 at $808 \mathrm{~nm}$. Samples were irradiated for $15 \mathrm{~min}$ with the laser at a power of $0.56 \mathrm{~W}$ and at a spot size of $6 \mathrm{~mm}$ $\left(2.0 \mathrm{~W} / \mathrm{cm}^{2}\right)$ and then cooled to room temperature.

\section{Cell culture}

MDA-MB-231 cells were obtained from the American Type Culture Collection (Manassas, VA, USA). Cells were grown in Dulbecco's Modified Eagle's Medium (DMEM) media supplemented with $10 \%$ fetal bovine serum (FBS), $1 \%$ penicillin-streptomycin, and 1\% 4-(2-hydroxyethyl)1-piperazineethanesulfonic acid (HEPES). Cells were incubated at $37^{\circ} \mathrm{C}$ and $5 \% \mathrm{CO}_{2}$.

\section{Cytocompatibility studies}

Cells were seeded onto 96-well plates at a cell density of 5,000 per well and incubated for $24 \mathrm{~h}$ prior to the addition of NPs. NP suspensions were dialyzed in water for $24 \mathrm{~h}$, after which they were transferred to a laminar flow hood. Prior to use, the NP suspensions were sterilized by filtration through a sterile $0.2-\mu \mathrm{m}$ polyethersulfone membrane filter. The NP suspensions were diluted in complete media without phenol red. NPs were added to the cells $(100 \mu \mathrm{L})$ at a starting concentration of $500 \mu \mathrm{g} / \mathrm{mL}$ and diluted by thirds to a final minimum concentration of $0.2 \mu \mathrm{g} / \mathrm{mL}$. Positive and negative controls were incubated with $100 \mu \mathrm{L}$ of media lacking NPs. The cells were incubated in the presence of NPs for $1.5 \mathrm{~h}$ or $12 \mathrm{~h}$. After the incubation time, the NP suspensions were removed and the cells were washed twice with Dulbecco's phosphate-buffered saline (DPBS) containing calcium and magnesium. Cells in the negative control were treated with methanol for $10 \mathrm{~min}$. The 3-(4,5-dimethylthiazol-2-yl)-2,5diphenyltetrazolium bromide (MTT) assay was used to determine the cell viability. The MTT assay is a colorimetric assay in which MTT is metabolized by mitochondrial dehydrogenases of live cells producing purple formazan crystals that are then dissolved for spectrophotometric analysis. ${ }^{26}$ The MTT reagent solution was prepared at a concentration of $0.5 \mathrm{mg} / \mathrm{mL}$ in a phenol red-free media and was sterile filtered. Cells were then incubated with $100 \mu \mathrm{L}$ of the MTT solution for $2.5 \mathrm{~h}$. After incubation, the MTT solution was carefully removed and replaced with $100 \mu \mathrm{L}$ of dimethyl sulfoxide. The plates were placed on an orbital shaker for $5 \mathrm{~min}$ to completely dissolve the formazan crystals. The absorbance of the samples was determined at 570 and $700 \mathrm{~nm}$. The background absorbance $(700 \mathrm{~nm})$ was subtracted from that of the formazan solution $(570 \mathrm{~nm})$. Each concentration was analyzed in replicates of six. Replicates were averaged and compared with the positive control.

\section{In vitro PTT ablation of MDA-MB-23 I cells}

PTT ablation studies were conducted in a custom-made incubator to emulate physiological temperature (Figure S1). A live/dead viability assay for mammalian cells was used to determine the photothermal ablation efficacy of the NPs. The cells were seeded at a density of 10,000 cells per well in 96-well plates and incubated for $24 \mathrm{~h}$ prior to use. NP suspensions were filtered through $0.2-\mu \mathrm{m}$ filters and diluted in DMEM without phenol red supplemented with $10 \% \mathrm{FBS}, 1 \%$ penicillin-streptomycin, and $1 \%$ HEPES. The media was removed, and the cells were washed twice with DPBS. The NP suspensions were then added at concentrations of $10,50,100$, and $500 \mu \mathrm{g} / \mathrm{mL}$, and the cells were incubated for $1.5 \mathrm{~h}$. The NP suspensions were then removed and replaced with DPBS prior to laser irradiation. Separate studies were conducted in which cells were irradiated in the presence of NPs after the 1.5-h incubation period.

For irradiation, 96-well plates were transferred to the temperature-controlled incubator where the samples were 
irradiated for 5 or $15 \mathrm{~min}$ intervals at a laser power of $0.8 \mathrm{~W}$ with a spot size of $3.8 \mathrm{~mm}\left(7 \mathrm{~W} / \mathrm{cm}^{2}\right)$. The cells were then incubated for $1 \mathrm{~h}$ after irradiation prior to determination of the extent of cell death. Ablation controls included cells exposed to NPs but not irradiated (dark control), cells exposed to laser irradiation in the absence of NPs (negative control), and cells killed with methanol (positive control). All studies were conducted in triplicate.

The live/dead working solution was made by diluting calcein acetoxymethyl (AM) and ethidium homodimer-1 (EthD-1) together in DPBS to 2.0 and $1.5 \mu \mathrm{M}$, respectively. After laser exposure and further incubation, the cell media was replaced with the live/dead assay working solution. The cells were incubated at room temperature for $30 \mathrm{~min}$ prior to imaging. The samples were imaged using an EVOS $^{\circledR}$ FL optical microscope that was equipped with red fluorescent protein $\left(\lambda_{\mathrm{EX}} 531 / 40 \mathrm{~nm}, \lambda_{\mathrm{EM}} 593 / 40 \mathrm{~nm}\right)$ and green fluorescent protein $\left(\lambda_{\mathrm{EX}} 470 / 22 \mathrm{~nm}, \lambda_{\mathrm{EM}} 525 / 50 \mathrm{~nm}\right)$ filter cubes. Images were analyzed using ImageJ to quantitate the extent of therapeutic effect using a previously published method. ${ }^{27,28}$ Specifically, the average level of green fluorescence (live cells) for each cell was measured and corrected for background fluorescence and cell area. This process was used to analyze the fluorescence of all cells in two to three images per condition. The percent viability was determined relative to that of the control.

\section{Results NP preparation}

The oxidative-emulsion polymerization process used for the preparation of the NPs could be monitored visually from the changes in color of the emulsion. Prior to addition of $\mathrm{FeCl}_{3}$, the monomer emulsions appeared yellow/green. Upon addition of the oxidant, the suspensions changed to a dark blue/ green color (Figure 1A). After removing excess surfactant by dialysis, the suspensions remained a dark blue/green color, which is the characteristic of NIR-absorbing conductive polymers in the doped state. This emulsion polymerization process yielded spherical NPs for both P1-PMD and PEDOTPMD, as can be seen from the TEM and SEM images (Figure 2A-D). Both polymer suspensions demonstrated strong absorbance in the NIR region (Figure $2 \mathrm{E}$ and $\mathrm{F}$ ), and
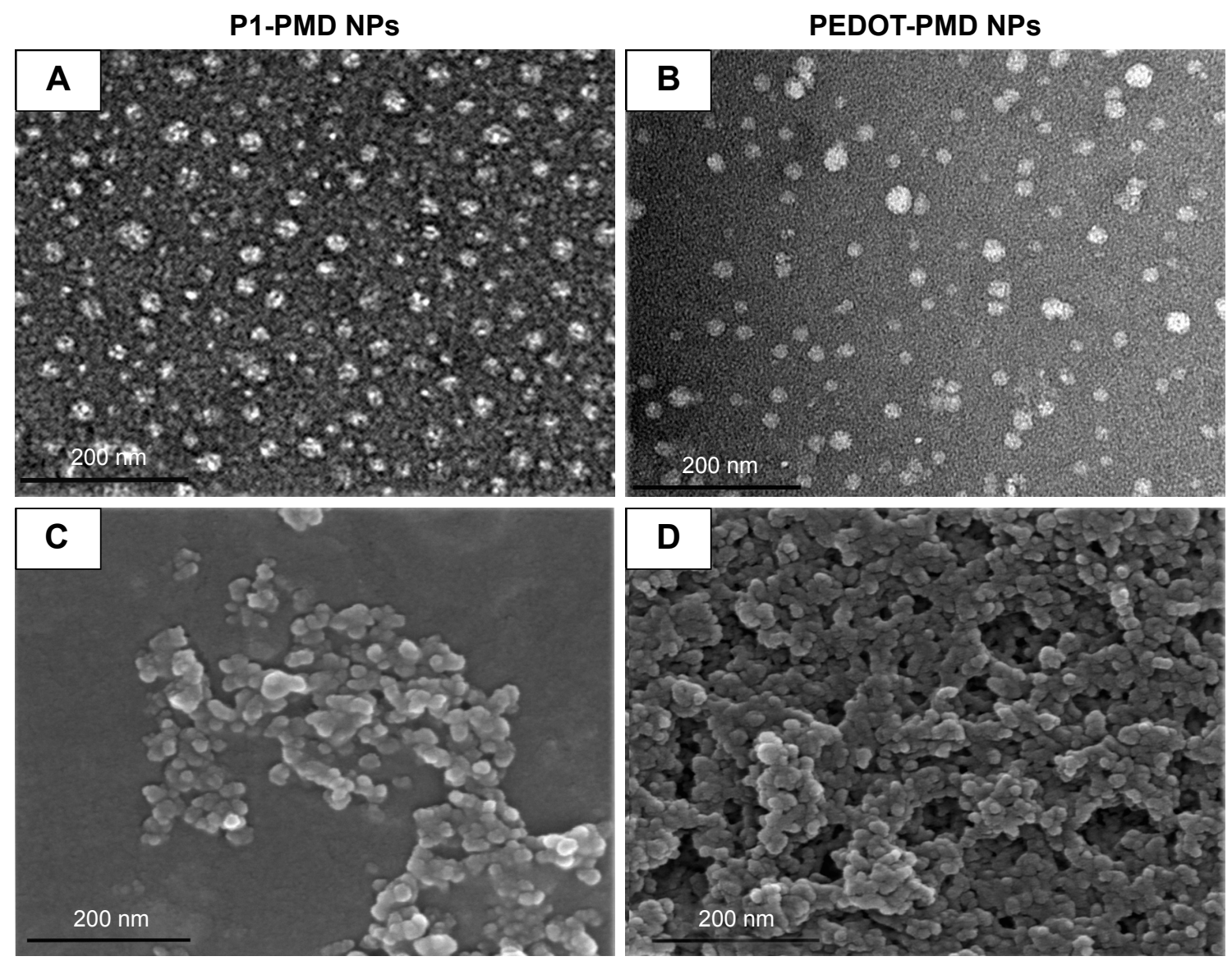

Figure 2 (Continued) 

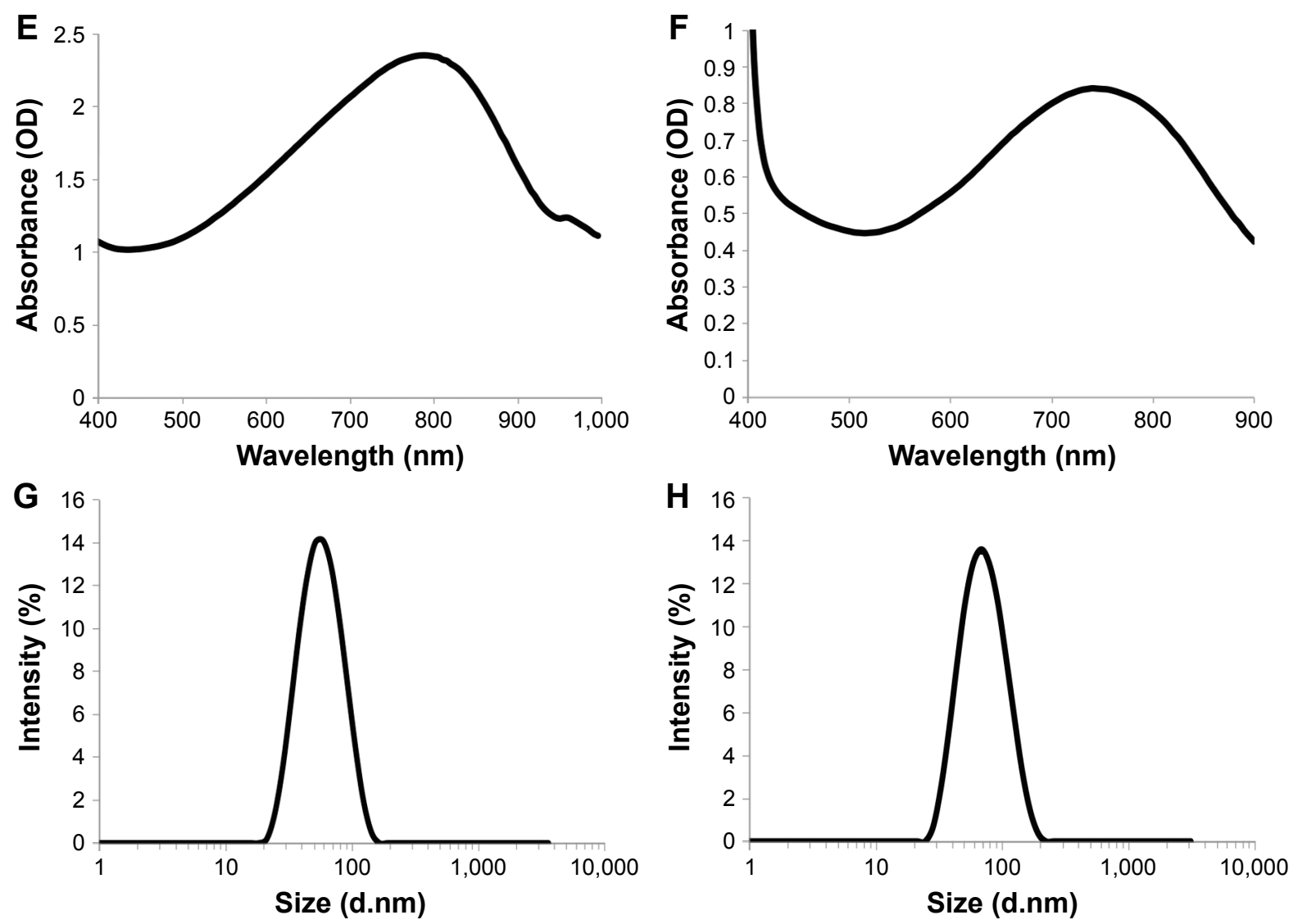

Figure 2 Characterization of PI-PMD and PEDOT-PMD NPs.

Notes: Transmission electron microscopy (A, B) and scanning electron microscopy (C, D) microscopy images of NPs. Absorption spectra (E, F) and dynamic light scattering size distribution of $(\mathbf{G}, \mathbf{H})$ NPs.

Abbreviations: NPs, nanoparticles; PI, poly(diethyl-4,4'-\{[2,5-bis(2,3-dihydrothieno[3,4-b][I,4]dioxin-5-yl)-I,4-phenylene]bis(oxy)\} dibutanoate); PEDOT, poly(3,4-ethylenedioxythiophene); DBSA, 4-dodecylbenzenesulfonic acid; PSS-co-MA, poly(4-styrenesulfonic acid-co-maleic acid); PI-PMD, PI:PSS-co-MA:DBSA; PEDOT-PMD, PEDOT: PSS-co-MA:DBSA.

unlike Clevios PH1000, both P1-PMD and PEDOT-PMD have distinct absorption rather than broad absorption bands (comparison is shown in Figure S2). Notably, differences in the chemical structure between P1-PMD and PEDOT-PMD resulted in differences in the peak absorption wavelengths for these two systems. Specifically, the absorption peak for P1-PMD (780 nm) was red-shifted compared to that of PEDOT-PMD (750 nm).

The NPs had an average diameter of $77 \mathrm{~nm}$ with a polydispersity index (PDI) of 0.132 for P1-PMD and $65 \mathrm{~nm}$ with a PDI of 0.183 for PEDOT-PMD (Figure $2 \mathrm{G}$ and $\mathrm{H}$ ) per DLS analysis. The size of the NPs is optimal for biomedical applications since it would enable intravenous administration and passive tumor targeting via the enhanced permeability and retention effect. ${ }^{29}$ The zeta potentials of both P1-PMD and PEDOT-PMD were highly negative at $-34 \pm 12.8$ and $-27 \pm 8.7 \mathrm{mV}$, respectively, as a result of the presence of the surfactants as part of the overall NP structure. Importantly, both NP suspensions were stable and could be easily filtered through $0.2-\mu \mathrm{m}$ filters, thus confirming that there was no NP aggregation.

\section{Effect of concentration of PTT activity of NP suspensions}

Figure $3 \mathrm{~A}$ and $\mathrm{B}$ shows the temperature change in both P1-PMD and PEDOT-PMD NP suspensions after 5 min of laser irradiation at $2 \mathrm{~W} / \mathrm{cm}^{2}$ followed by over $6 \mathrm{~min}$ of cooling. The study was conducted at room temperature. P1-PMD NP suspensions exhibited temperature changes of $\sim 1.7^{\circ} \mathrm{C}-43^{\circ} \mathrm{C}$ at concentrations of $10-500 \mu \mathrm{g} / \mathrm{mL}$, whereas PEDOT-PMD NP suspensions increased $\sim 1.5^{\circ} \mathrm{C}-33^{\circ} \mathrm{C}$ in this same concentration range. For both suspensions, there is a linear relationship between the NP concentration and the temperature change, as shown in the insets of Figure $3 \mathrm{~A}$ and $\mathrm{B}$. The differences in temperature changes observed between the two types of NPs are largely associated with the differences in absorbance at the laser wavelength $(808 \mathrm{~nm})$. As shown in Figure 2, the peak absorption of P1-PMD NPs more closely matches the laser wavelength $(808 \mathrm{~nm})$ than that of PEDOT-PMD NPs. At equal concentrations, P1-PMD NPs are able to absorb more energy from the laser than PEDOT-PMD NPs. 

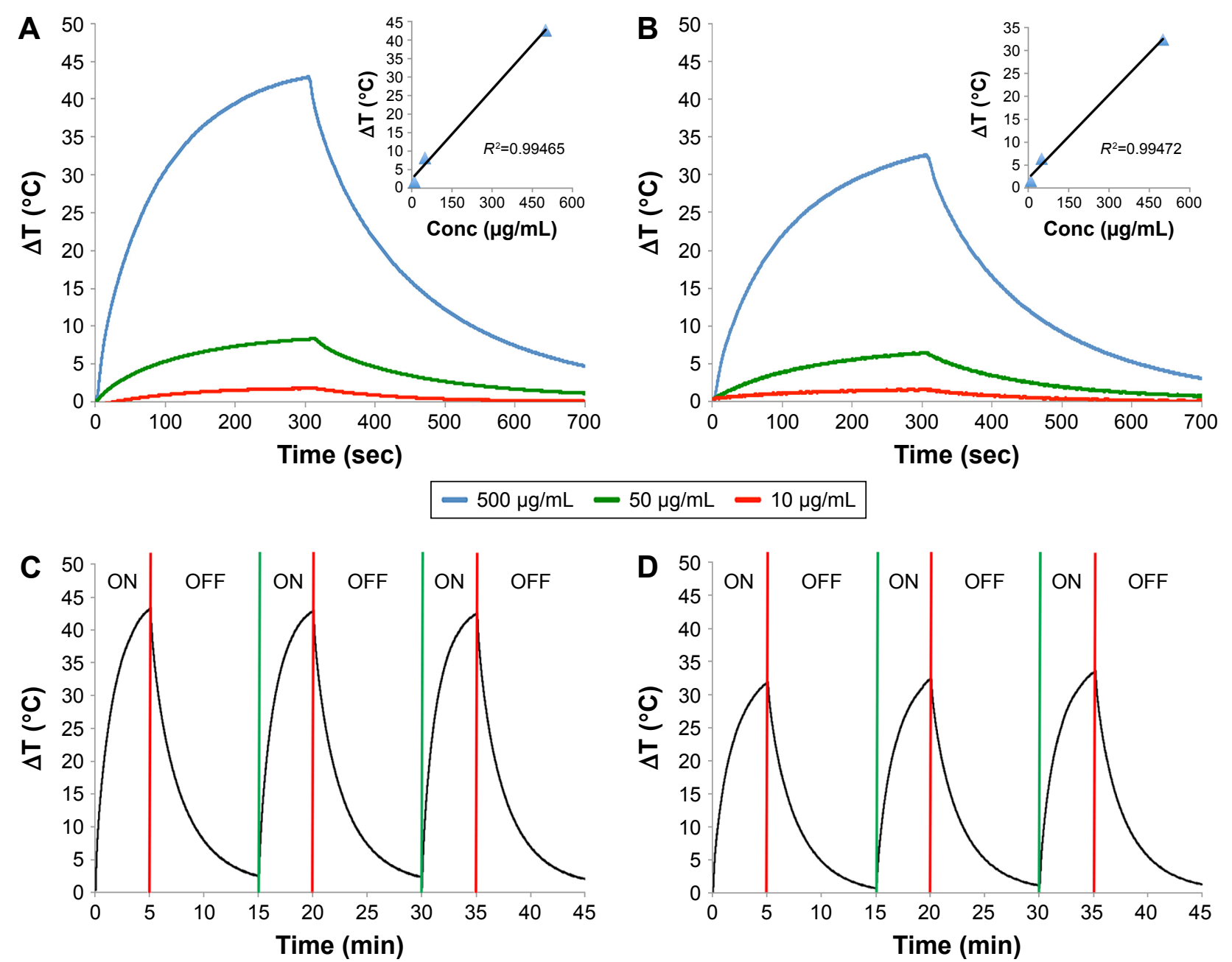

$50 \mu \mathrm{g} / \mathrm{mL} \quad-10 \mu \mathrm{g} / \mathrm{mL}$ followed by cooling in the absence of irradiation. Cycled laser-mediated irradiation (ON) and cooling in the absence of irradiation (OFF) for PI-PMD (C) and PEDOT-PMD (D) NP suspensions.

Abbreviations: NPs, nanoparticle; PI, poly(diethyl-4,4'-\{[2,5-bis(2,3-dihydrothieno[3,4-b][I,4]dioxin-5-yl)-I,4-phenylene]bis(oxy)\} dibutanoate); PEDOT, poly(3,4-ethylenedioxythiophene); DBSA, 4-dodecylbenzenesulfonic acid; PSS-co-MA, poly(4-styrenesulfonic acid-co-maleic acid); PI-PMD, PI:PSS-co-MA:DBSA; PEDOT-PMD, PEDOT: PSS-co-MA:DBSA.

Cycled laser irradiation of P1-PMD and PEDOT-PMD NP suspensions at $500 \mu \mathrm{g} / \mathrm{mL}$ did not result in changes in the laser-induced heating of the suspensions (Figure 3C and D). The ability to attain identical temperatures upon repeated cycles of irradiation suggests that both P1-PMD and PEDOTPMD NPs are photostable and can be irradiated multiple times without undergoing degradation. TEM images of the NPs after irradiation reinforce this observation because no significant difference in size or morphology is seen (Figure S3). Photostability is an important characteristic for photothermal agents as it could enable repeated treatment cycles.

\section{PTT conversion efficiency $\left(\eta_{T}\right)$}

$\mathrm{NP}$ suspensions at equal OD at the laser wavelength $(808 \mathrm{~nm})$ were irradiated until they reached a steady state at which the rate of heat gain due to PTT conversion by the
NPs, water, and sample holder equaled the heat output to the surroundings, leading to a constant sample temperature (Figure 4A). The laser was then turned off, and the suspensions were allowed to cool back to room temperature. Using Equation 11, the $\eta_{T}$ for P1-PMD and PEDOT-PMD were calculated to be $\sim 50 \%$ and $53 \%$, respectively, that is similar to that of Clevios PH1000 and higher than those of GNRs and GNSs (Figure 4B).

\section{Cytocompatibility studies}

Cell viability after 1.5 - and 12 -h exposure periods can be seen in Figure 5. Neither P1-PMD nor PEDOT-PMD caused any significant decrease in cell viability after $1.5 \mathrm{~h}$ of exposure to NP concentrations up to $500 \mu \mathrm{g} / \mathrm{mL}$. After $12 \mathrm{~h}$ of exposure, slightly lower cell viabilities were observed in cells exposed to high concentrations of NPs, resulting in cell viabilities 

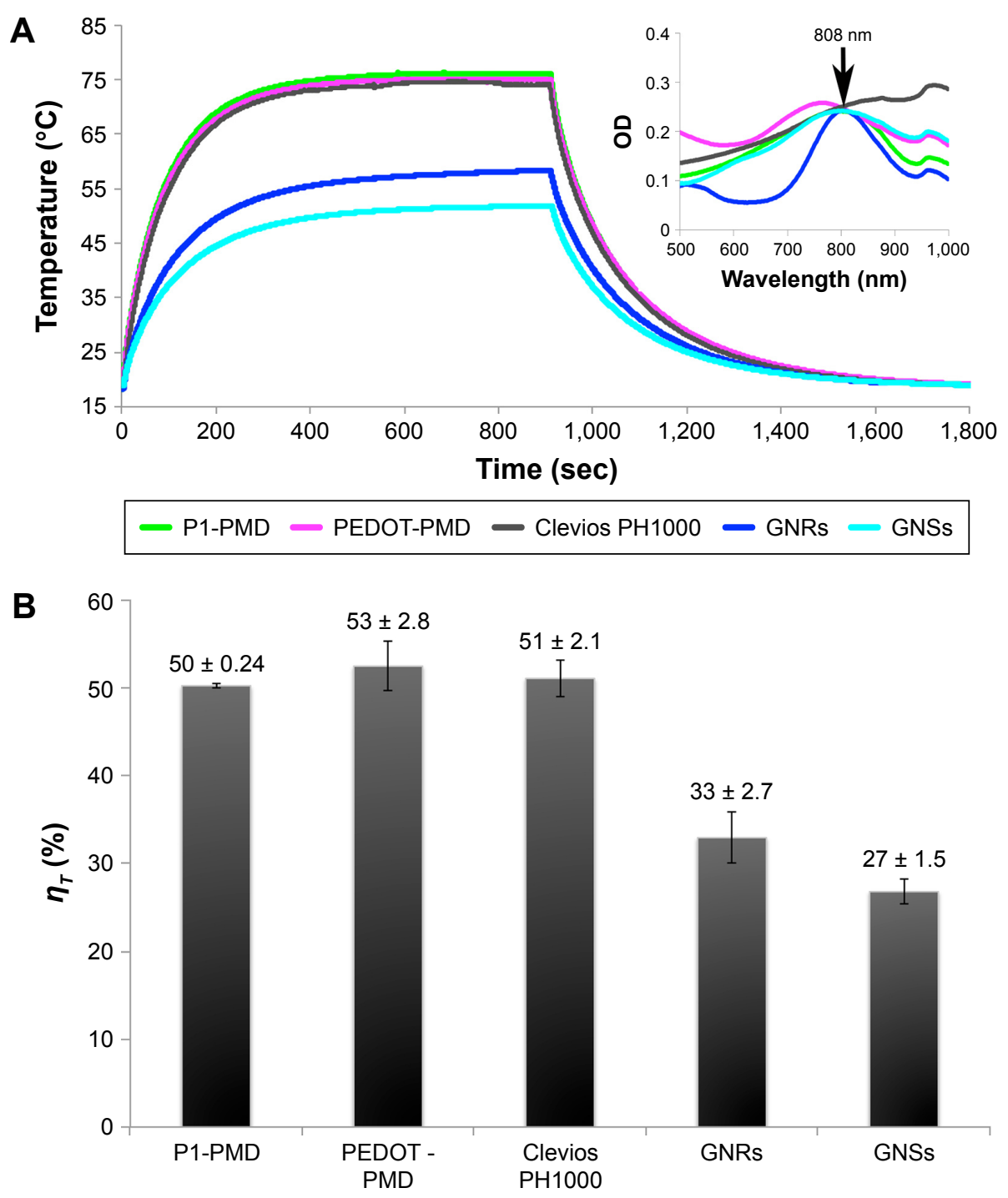

Figure 4 Photothermal conversion efficiency $\left(\eta_{T}\right)$ of NPs.

Notes: (A) Temperature of PI-PMD NPs, PEDOT-PMD NPs, Clevios PHI000, GNRs, and GNSs suspensions at equal OD that were irradiated with an 808-nm laser at $2 \mathrm{~W} / \mathrm{cm}^{2}$ until steady state and then allowed to cool. (B) $\eta_{T}$ of all NPs. Error bar represents standard deviation for sample replicates ( $\mathrm{n}=3$ ).

Abbreviations: GNRs, gold nanorods; GNSs, gold nanoshells; NPs, nanoparticles; OD, optical density; PI, poly(diethyl-4,4'-\{[2,5-bis(2,3-dihydrothieno[3,4-b][I,4]dioxin5-yl)-I,4-phenylene]bis(oxy)\} dibutanoate); PEDOT, poly(3,4-ethylenedioxythiophene); DBSA, 4-dodecylbenzenesulfonic acid; PSS-co-MA, poly(4-styrenesulfonic acid-comaleic acid); PI-PMD, PI:PSS-co-MA:DBSA; PEDOT-PMD, PEDOT:PSS-co-MA:DBSA.

of $\sim 80 \%$ of control for cells exposed to both P1-PMD and PEDOT-PMD NPs at the highest concentration of $500 \mu \mathrm{g} / \mathrm{mL}$. It should be noted that all further cell studies were conducted after $1.5 \mathrm{~h}$ of exposure to the NPs.

\section{PTT ablation studies}

Prior to in vitro studies, the absorbance of NPs suspended in media was measured (Figure S4). No blueshift in the peak absorption was observed indicating that the NPs were stable in their oxidized state, despite the presence of salts and serum. For PTT ablation studies, MDA-MB-231 breast cancer cells were exposed to NPs for $1.5 \mathrm{~h}$. After exposure, the NP suspensions were replaced with DPBS prior to laser irradiation. Fluorescence microscopy images of cells labeled with the live/dead assay are shown in Figures 6 and 7, while quantification of fluorescence from images is shown in Figure S5. In these images, viable cells are green, while dead cells are red.

Significant cell ablation was achieved in cells irradiated after exposure to P1-PMD NPs at concentrations of $50-500 \mu \mathrm{g} / \mathrm{mL}$ for either 5 or $15 \mathrm{~min}$ (Figures 6 and S5). The lower $10 \mu \mathrm{g} / \mathrm{mL}$ concentration did not result in significant cell death with up to 15 min of irradiation. For PEDOT-PMD NPs, cell ablation was achieved in cells irradiated after exposure to NPs at concentrations of $500 \mu \mathrm{g} / \mathrm{mL}$ with 5 -min irradiation and $50-500 \mu \mathrm{g} / \mathrm{mL}$ with $15-\mathrm{min}$ irradiation 

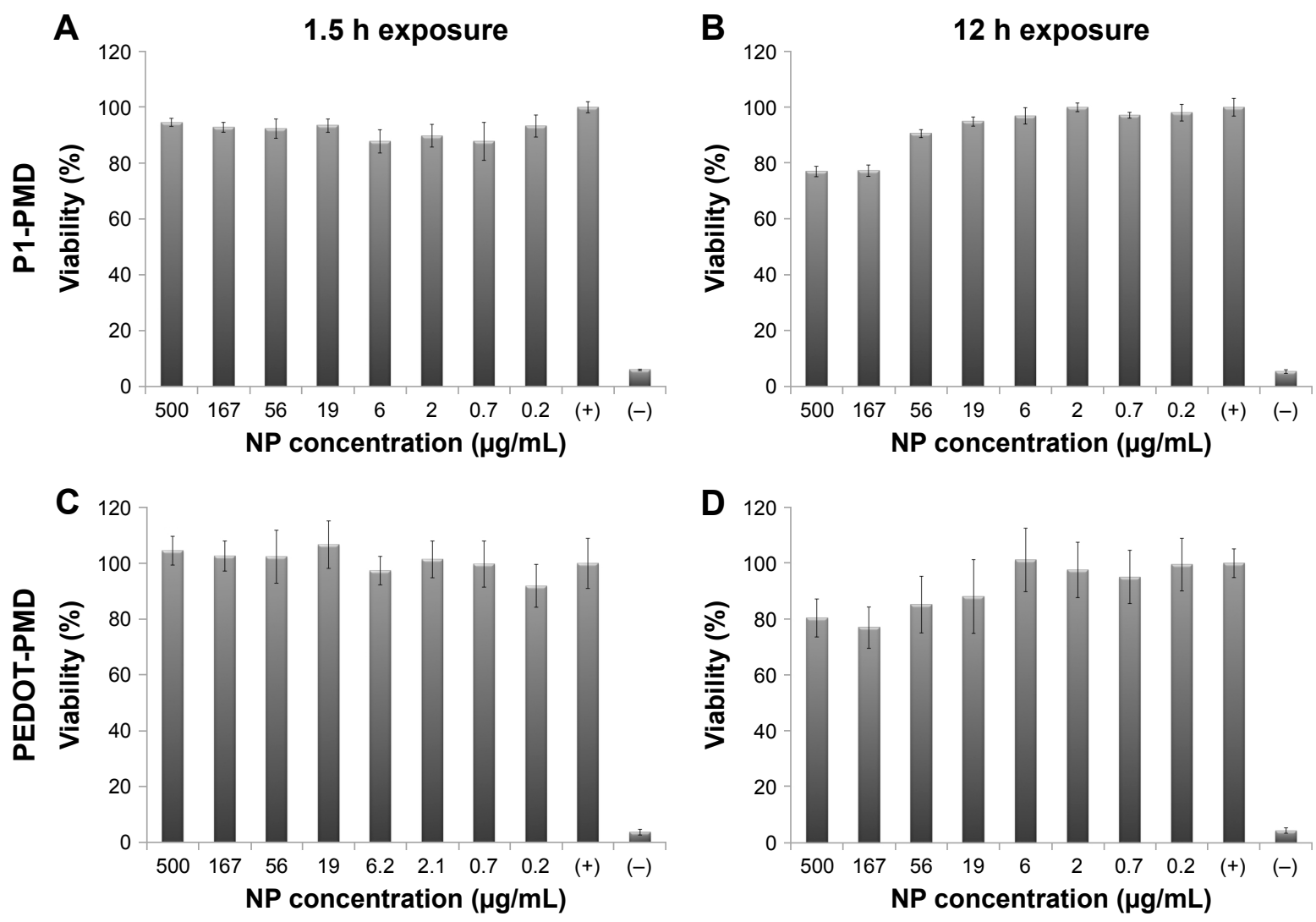

Figure 5 Cytocompatibility of PI-PMD and PEDOT-PMD NPs in MDA-MB-23I breast cancer cells determined with the MTT assay.

Notes: Data shown as percent viability relative to positive control (+), which consists of cells cultured in NP-free media. Negative control (-) represents cells killed with methanol. Error bars represent the standard deviation between replicates ( $\mathrm{n}=6$ ). Cells exposed to (A) PI-PMD NPs for I.5 h, (B) PI-PMD NPs for I2 h, (C) PEDOT-PMD NPs for $1.5 \mathrm{~h}$, and (D) PEDOT-PMD NPs for $12 \mathrm{~h}$.

Abbreviations: MTT, 3-(4,5-dimethylthiazol-2-yl)-2,5-diphenyltetrazolium bromide; NP, nanoparticle; PI, poly(diethyl-4,4'-\{[2,5-bis(2,3-dihydrothieno[3,4-b][I,4]dioxin5-yl)-I,4-phenylene]bis(oxy)\} dibutanoate); PEDOT, poly(3,4-ethylenedioxythiophene); DBSA, 4-dodecylbenzenesulfonic acid; PSS-co-MA, poly(4-styrenesulfonic acid-comaleic acid); PI-PMD, PI:PSS-co-MA:DBSA; PEDOT-PMD, PEDOT:PSS-co-MA:DBSA.

(Figures 7 and S5). Cells exposed to NPs in the absence of laser irradiation (dark control) and cells irradiated in the absence of NPs (negative control) showed little cell death for both samples. The improved cell-killing ability of P1-PMD NPs at low concentrations compared with PEDOT-PMD NPs is potentially a result of the spectral differences of these two NP types; the absorption peak for P1-PMD NP more closely aligns with the wavelength of the laser used in these studies, thereby producing a stronger photothermal effect at the equal concentrations.

It is important to note that in these studies, ablation is caused by NPs that have either adhered to or entered the cells in the 1.5-h period of exposure prior to laser irradiation since the NP suspensions were removed. Separate ablation studies were carried out with irradiation in the presence of NPs in which bulk solution heating occurs. In these studies, complete cell ablation was achieved with P1-PMD and PEDOT-PMD NPs at concentrations $\leq 10 \mu \mathrm{g} / \mathrm{mL}$ (Figure S6). These data confirm that the NPs themselves are generating enough heat to cause cell death.

\section{Discussion}

In this study, we have reported the preparation of P1-PMD and PEDOT-PMD by oxidative-emulsion polymerization, yielding spherical NPs smaller than $100 \mathrm{~nm}$. While emulsion polymerization has been previously used to produce CPNPs of PEDOT and polypyrrole stabilized in water, ${ }^{13,22}$ to the best of our knowledge emulsion polymerization has not been explored on more complex insoluble conductive polymers, such as P1. Han et al reported the synthesis of PEDOT:PSSco-MA NPs using spray emulsion polymerization, yielding a stable aqueous colloidal suspension of NPs. ${ }^{22}$ Likewise, Yang et al reported the synthesis of polypyrrole NPs by oxidative-emulsion polymerization, resulting in 100-nm spherical particles. ${ }^{13}$ Sun and Hagner reported the synthesis of rod-shaped PEDOT nanowires in which poly(acrylic acid) was used as the stabilizer. ${ }^{30}$ Rod-shaped morphology is a facet of the rigid backbone in conductive polymers, which reduces flexibility and leads to the formation of sheets that can stack due to $\pi-\pi^{*}$ interactions. In our work, the use of DBSA and PSS-co-MA as surfactants enabled the formation 

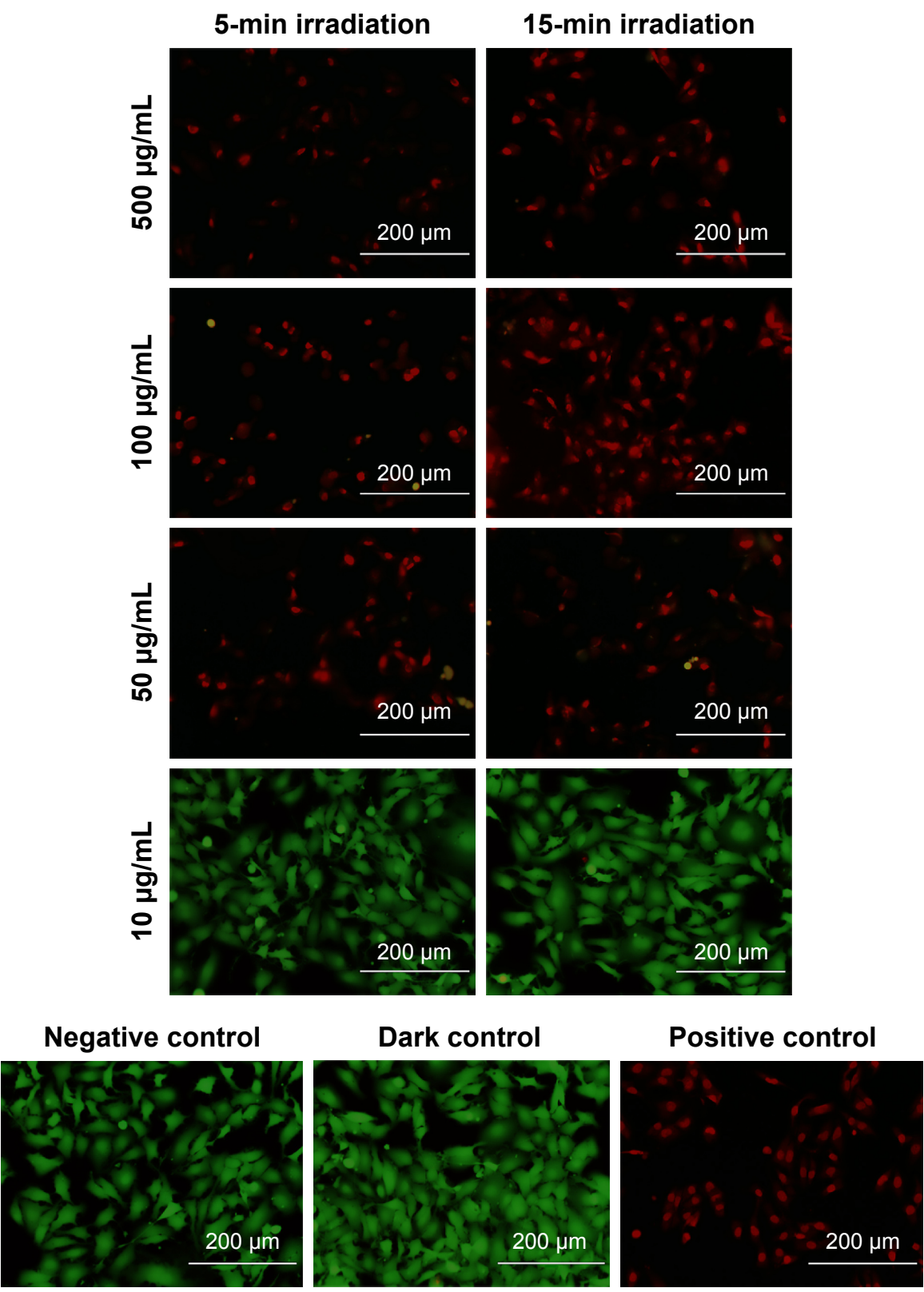

Figure 6 Photothermal ablation of MDA-MB-23I cells exposed to PI-PMD NPs for $1.5 \mathrm{~h}$ and irradiated with $808-\mathrm{nm}$ laser at 7 W/cm² after NPs were removed and replaced with Dulbecco's phosphate-buffered saline.

Notes: Green represents live cells and red represents dead cells. Images are overlays of both green and red channels. Negative control consists of cells in NP-free media and not exposed to laser. Dark control consists of cells exposed to NPs, but not irradiated. Positive control consists of cells killed with methanol. Scale bars $=200 \mu \mathrm{m}$.

Abbreviations: NPs, nanoparticles; PI, poly(diethyl-4,4'-\{[2,5-bis(2,3-dihydrothieno[3,4-b][I,4]dioxin-5-yl)-I,4-phenylene]bis(oxy)\} dibutanoate); DBSA, 4-dodecylbenzenesulfonic acid; PSS-co-MA, poly(4-styrenesulfonic acid-co-maleic acid); PI-PMD, PI:PSS-co-MA:DBSA.

of micelles that lead to the formation of spherical NPs even with the larger M1 monomer.

The negative zeta potential of the NPs confirmed intimate interaction of the anionic surfactants with the positively charged polymer. In fact, the anionic surfactants act as dopants, stabilizing the polymers in their oxidized form and stably becoming a part of the NP structure. The state of these polymers dramatically affects their absorbance; in the neutral, reduced state, the absorbance of these polymers blueshifts to the visible range in comparison to that in the oxidized state. ${ }^{31}$ The highly negative zeta potentials obtained with both NPs in addition indicate that the NP suspensions have high colloidal stability mediated by interparticle charge repulsion. ${ }^{32}$ In fact, the NPs are not able to dissolve in organic solvents in which the monomers would normally be soluble (Figure S7) because of their interaction with the anionic surfactants.

While significant work has been done on the study of GNPs as PTT agents, CPNPs are still relatively new materials in the PTT therapy field. The majority of the studies 


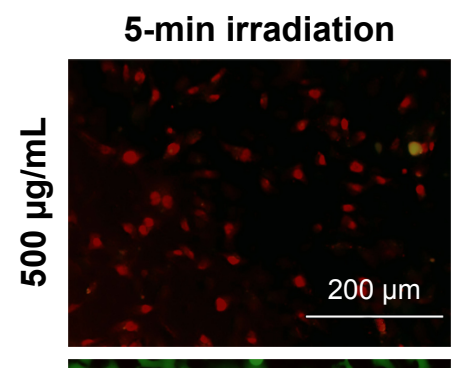

15-min irradiation
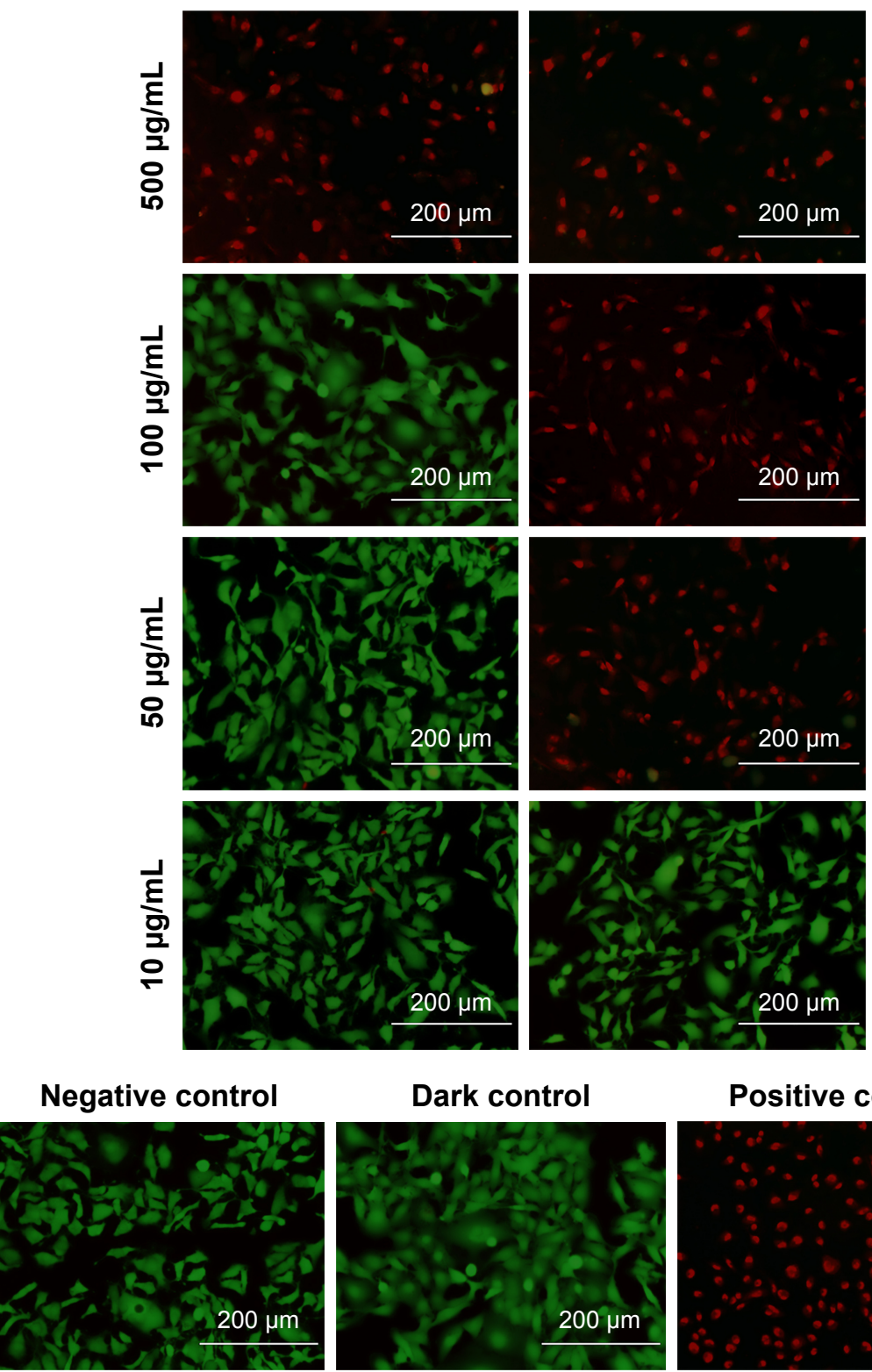

\section{Positive control}

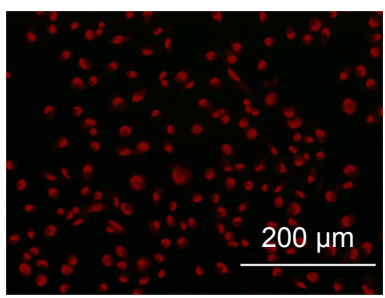

Figure 7 PTT ablation of MDA-MB-23I cells exposed to PEDOT-PMD NPs for $1.5 \mathrm{~h}$ and irradiated with $808-\mathrm{nm}^{2}$ laser at 7 W/cm² after NPs were removed and replaced with Dulbecco's phosphate-buffered saline.

Notes: Green represents live cells and red represents dead cells. Images are overlays of both green and red channels. Negative control consists of cells in NP-free media and not exposed to laser. Dark control consists of cells exposed to NPs, but not irradiated. Positive control consists of cells killed with methanol. Scale bars $=200 \mu \mathrm{m}$.

Abbreviations: NPs, nanoparticles; PEDOT, poly(3,4-ethylenedioxythiophene); DBSA, 4-dodecylbenzenesulfonic acid; PSS-co-MA, poly(4-styrenesulfonic acid-co-maleic acid); PEDOT-PMD, PEDOT:PSS-co-MA:DBSA; PTT, photothermal therapy.

demonstrating the potential of CPNPs as PTT agents have been carried out by Liu et al. ${ }^{12,13,33}$ Their group demonstrated that polypyrrole and PEDOT:PSS NPs can both act as effective PTT agents. ${ }^{12,13}$ Separately, NPs composed of 2-ethylhexyl cyclopentadithiophene copolymerized with 2,1,3-benzothiadiazole or 2,1,3-benzoselenadiazole synthesized by MacNeill et al also proved to be effective PTT agents. ${ }^{15}$ It has also been reported that CPNPs demonstrate very high photostability over several cycles of continuous laser irradiation in comparison to the behavior of GNPs. ${ }^{14}$
Our CPNPs also demonstrated high photostability, as demonstrated by their ability to achieve the same temperature and to maintain their shape after consecutive cycles of irradiation.

While the PTT conversion efficiency of certain types of GNPs has been previously defined,,$^{23,25,34}$ to the best of our knowledge, there have not been any studies that compare the PTT conversion efficiency of GNPs to those of CPNPs. As per our results, both P1-PMD and PEDOT-PMD have PTT conversion efficiencies $>50 \%$ (Figure 3). In fact, the PTT conversion efficiencies of our NPs were greater than those of 
the GNRs and GNSs used in this study. Pattani and Tunnell reported PTT conversion efficiencies of $~ 25 \%$ and $50 \%$ for PEGylated GNSs and GNRs. ${ }^{23}$ In comparison, Cheng et al reported PTT conversion efficiencies of $2.5 \%$ and $8.25 \%$ for non-PEGylated GNRs and GNSs; $;{ }^{34}$ however, these studies utilized a different method for the calculation of PTT conversion efficiency. In our work, non-PEGylated GNSs and PEGylated GNRs showed PTT conversion efficiencies of 27\% and $33 \%$, respectively. Differences in PTT conversion efficiency may be associated with differences in NP sizes, shapes, and surface chemistry, including the presence or absence of PEGylation. It is known that aggregation affects the PTT conversion efficiency; therefore, it is possible that the more stable PEGylated GNPs exhibit higher PTT conversion efficiencies than non-PEGylated GNPs. Our NPs form much more stable colloidal suspensions than the highly dense GNPs (whether PEGylated or not), which in turn could account for the higher PTT conversion efficiency of our NPs.

Cell studies were carried out using MDA-MB-231 as an in vitro model of cancer. This cell line is a model of triple negative breast cancer because it lacks expression of the estrogen, progesterone, and human epidermal growth factor receptor 2 (HER-2)/Neu receptors. ${ }^{35}$ Triple-negative breast cancers tend to be more aggressive and result in a worse prognosis for the patients. In addition, triple-negative breast cancers cannot be treated with hormone or HER-2/Neu inhibitors, thus limiting therapeutic options to surgery and chemotherapy. Consequently, our work demonstrating the effectiveness of our NPs at mediating PTT ablation of these cells is significant.

As shown in Figure 3, both P1-PMD and PEDOT-PMD NPs can enable laser-induced bulk solution heating of over $5^{\circ} \mathrm{C}$ at $50 \mu \mathrm{g} / \mathrm{mL}$ when irradiated at a laser power of $2 \mathrm{~W} / \mathrm{cm}^{2}$. From these data, it was expected that both P1-PMD and PEDOT-PMD NPs could demonstrate enough temperature increase to substantially damage cells. An increase of $5^{\circ} \mathrm{C}$ or greater can lead to irreversible cell damage. ${ }^{4}$

The extent of cell death after laser irradiation was determined using a live/dead assay based on calcein AM and EthD-1. Nonfluorescent calcein AM is enzymatically converted to fluorescent calcein by intracellular esterases of live cells. ${ }^{36}$ EthD-1 enters cells with a compromised membrane; once in the cell, EthD-1's fluorescence is increased 40-fold upon binding to nucleic acids and thereby labeling dead cells. ${ }^{36}$ As shown, both types of NPs were able to mediate laser-induced cell ablation after a very short incubation period, whether excess NPs were removed. P1-PMD NPs showed efficacy at lower concentrations, possibly because their absorption peak better matches the laser wavelength, leading to enhanced light absorption at equal concentrations. These results suggest that these NPs have significant potential as agents for PTT therapy.

In our studies, the mechanism of cell death caused by NPmediated PTT ablation was not explored. It was first reported by Tong and Cheng that ablation by GNRs was mediated by apoptosis. ${ }^{37}$ However, more recently, a study conducted by Pattani et al determined that the mechanism of cell death is dependent on the internalization of the GNPs into the cells. ${ }^{38}$ NPs that have only reached the cell membrane tend to induce cell necrosis, while those that are internalized near organelles tend to induce cell apoptosis. ${ }^{38}$ While these studies can be correlated to other GNPs, to our knowledge, there have not been any studies investigating cell death mechanisms associated with PTT therapy enabled by polymeric NPs. This will be a topic of future investigation. Specifically, we plan to carry out further biochemical investigation of caspase activation, phosphatidylserine presentation, and p21 expression as a function of NP concentration, NP-cell interaction time, laser irradiation time, and laser intensity to gain a more thorough understanding of the potential of these photothermal ablation agents. In addition, we will investigate the potential of these NPs to act as carriers for controlled delivery of therapeutic agents for dual PTT ablation and chemotherapy.

\section{Acknowledgments}

This work was supported, in part, by the National Science Foundation Partnership in Research and Education in Materials (DMR-1205670), the Texas Emerging Technology Fund, The Robert A. Welch Foundation (AI-0045), the Texas State Research Enhancement Program, and the Texas State University Doctoral Research Support Fellowship to TC. We would also like to thank Nanospectra Biosciences, Inc. and NanoHybrids, Inc. for graciously providing GNSs and GNRs.

\section{Disclosure}

The authors report no conflicts of interest in this work.

\section{References}

1. American Cancer Society. Cancer Facts \& Figures; 2016. Available from: http://www.cancer.org/acs/groups/content/@research/documents/ document/acspc-047079.pdf. Accessed December 12, 2016.

2. Deasy S, Szczepanek K, Hunter K. Targeting metastatic breast cancer: problems and potential. F1000Research. 2015;4:1-5.

3. IkedaS, Hansel DE, Kurzrock R. Beyond conventional chemotherapy: emerging molecular targeted and immunotherapy strategies in urothelial carcinoma. Cancer Treat Rev. 2015;41(8):699-706.

4. Chicheł A, Skowronek J, Kubaszewska M, Kanikowski M. Hyperthermiadescription of a method and a review of clinical applications. Reports Pract Oncol Radiother. 2007;12:267-275.

5. Wust $P$, Hildebrandt B, Sreenivasa G, et al. Hyperthermia in combined treatment of cancer. Lancet Oncol. 2002;3(8):487-497. 
6. del Pino P, Pelaz B. Hyperthermia using Inorganic Nanoparticles. In: de la Fuente JM, Grazu V, editors. Nanobiotechnology: Inorganic Nanoparticles vs Organic Nanoparticles. Volume 3. Oxford: Elsevier; 2013:309-335.

7. Donkol RH, Nammi AA. Hyperthermia tissue ablation in radiology. In: Huilgol N, editor. Hyperthermia. Croatia, Europe: InTech; 2013: $145-170$.

8. Huang X, Jain PK, El-Sayed IH, El-Sayed MA. Plasmonic photothermal therapy (PPTT) using gold nanoparticles. Lasers Med Sci. 2008; 23(3):217-228.

9. Huang X, El-Sayed IH, Qian W, El-sayed MA. Cancer cell imaging and photothermal therapy in the near-infrared region by using gold nanorods. J Am Chem Soc. 2006;128(6):2115-2120.

10. Hirsch LR, Jackson JB, Lee A, Halas NJ, West JL. A whole blood immunoassay using gold nanoshells. Anal Chem. 2003;75(10):2377-2381.

11. Hirsch LR, Stafford RJ, Bankson JA, et al. Nanoshell-mediated nearinfrared thermal therapy of tumors under magnetic resonance guidance. Proc Natl Acad Sci US A. 2003;100(23):13549-13554.

12. Cheng L, Yang K, Chen Q, Liu Z. Organic stealth nanoparticles for highly effective in vivo near-infrared photothermal therapy of cancer. ACS Nano. 2012;6(6):5605-5613.

13. Yang K, Xu H, Cheng L, Sun C, Wang J, Liu Z. In vitro and in vivo near-infrared photothermal therapy of cancer using polypyrrole organic nanoparticles. Adv Mater. 2012;24(41):5586-5592.

14. Zha Z, Yue X, Ren Q, Dai Z. Uniform polypyrrole nanoparticles with high photothermal conversion efficiency for photothermal ablation of cancer cells. Adv Mater. 2013;25(5):777-782.

15. Macneill CM, Coffin RC, Carroll DL, Levi-Polyachenko NH. Low band gap donor-acceptor conjugated polymer nanoparticles and their NIR-mediated thermal ablation of cancer cells. Macromol Biosci. 2012;13(1):1-7.

16. Zhang W, Guo Z, Huang D, Liu Z, Guo X, Zhong H. Synergistic effect of chemo-photothermal therapy using PEGylated graphene oxide. Biomaterials. 2011;32(33):8555-8561.

17. Lin Z, Liu Y, Ma X, et al. Photothermal ablation of bone metastasis of breast cancer using PEGylated multi-walled carbon nanotubes. Sci Rep. 2015;5:11709.

18. Moon HK, Lee SH, Choi HC. In vivo near-infrared mediated tumor destruction by photothermal effect of carbon nanotubes. ACS Nano. 2013;3(11):3707-3713.

19. Amb CM, Dyer AL, Reynolds JR. Navigating the color palette of solution-processable electrochromic polymers. Chem Mater. 2011;23(3): $397-415$.

20. Cantu T, Rodier B, Iszard Z, et al. Electroactive polymer nanoparticles exhibiting photothermal properties. J Vis Exp. 2016:(107).

21. Winkel KL, Carberry JR, Irvin JA. Synthesis and electropolymerization of 3,5-bis-(3,4-ethylenedioxythien-2-yl)-4,4-dimethyl isopyrazole: a donor-acceptor-donor monomer. J Electrochem Soc. 2013; 160(8):G111-G116.

22. Han YK, Yih JN, Chang MY, et al. Facile synthesis of aqueous-dispersible nano-PEDOT:PSS-co-MA core/shell colloids through spray emulsion polymerization. Macromol Chem Phys. 2011;212(4):361-366.
23. Pattani VP, Tunnell JW. Nanoparticle-mediated photothermal therapy: a comparative study of heating for different particle types. Lasers Surg Med. 2012;44(8):675-684.

24. Roper DK, Ahn W, Hoepfner M. Microscale heat transfer transduced by surface plasmon resonant gold nanoparticles. J Phys Chem C Nanomater Interfaces. 2007;111(9):3636-3641.

25. Cole JR, Mirin NA, Knight MW, Goodrich GP, Halas NJ. Photothermal efficiencies of nanoshells and nanorods for clinical therapeutic applications. J Phys Chem C. 2009;113(28):12090-12094.

26. Morgan D. Tetrazolium (MTT) assay for cellular viability and activity. In: Morgan D editor. Methods in Molecular Biology. Humana Press Inc; 1998 : 179-184. Available from: http://link.springer.com/protocol/10.1385\%2F089603-448-8\%3A179. Accessed December 12, 2016.

27. Burgess A, Vigneron S, Brioudes E, Jabbe JC, Lorca T, Castro A. Loss of human Greatwall results in G2 arrest and multiple mitotic defects due to deregulation of the cyclin B-Cdc2/PP2A balance. Proc Natl Acad Sci U S A. 2010;107(28):12564-12569.

28. McCloy RA, Rogers S, Caldon CE, Lorca T, Castro A, Burgess A. Partial inhibition of Cdk1 in G 2 phase overrides the SAC and decouples mitotic events. Cell Cycle. 2014;13(9):1400-1412.

29. Danhier F, Feron O, Preat V. To exploit the tumor microenvironment: passive and active tumor targeting of nanocarriers for anti-cancer drug delivery. J Control Release. 2010;148(2):135-146.

30. Sun X, Hagner M. Novel poly (acrylic acid)-mediated formation of conducting polymer nanowires. Macromolecules. 2007;25:8537-8539.

31. Winkel KL, Carberrya JR, Wooda LM, et al. Donor-acceptor-donor polymers utilizing pyrimidine-based acceptors. React Funct Polym. 2014;83:113-122.

32. Chen H, Yang S, Zhou T, Xu J, Hu J, Xing D. Synthesis and characterization of an HSP27-targeted nanoprobe for in vivo photoacoustic imaging of early nerve injury. Nanomedicine. 2016;12(6):1453-1462.

33. Cheng L, He W, Gong H, et al. PEGylated micelle nanoparticles encapsulating a non-fluorescent near-infrared organic dye as a safe and highly-effective photothermal agent for in vivo cancer therapy. Adv Funct Mater. 2013;23(47):5893-5902.

34. Cheng F, Chen C, Yeh C. Comparative efficiencies of photothermal destruction of malignant cells using antibody-coated silica@Au nanoshells, hollow Au/Ag nanospheres and Au nanorods. Nanotechnology. 2009;20(42):425104

35. Chavez KJ, Garmella SV, Lipkowitz S. Triple negative breast cancer:one tool in the search for better treatment of triple negative breast cancer. Breast Dis. 2011;32(1-2):35-48.

36. Wilson NH, Hardisty JF, Hayes JR. Principles and Methods of Toxicology. Boca Raton, Florida, USA: CRC Press; 2008.

37. Tong L, Cheng JX. Gold nanorod-mediated photothermolysis induces apoptosis of macrophases via damage of mitochondria. Nanomedicine (Lond). 2009;4(3):265-276.

38. Pattani VP, Shah J, Atalis A, Sharma A, Tunnell JW. Role of apoptosis and necrosis in cell death induced by nanoparticle-mediated photothermal therapy. J Nanoparticle Res. 2015;17:20. 


\section{Supplementary materials}
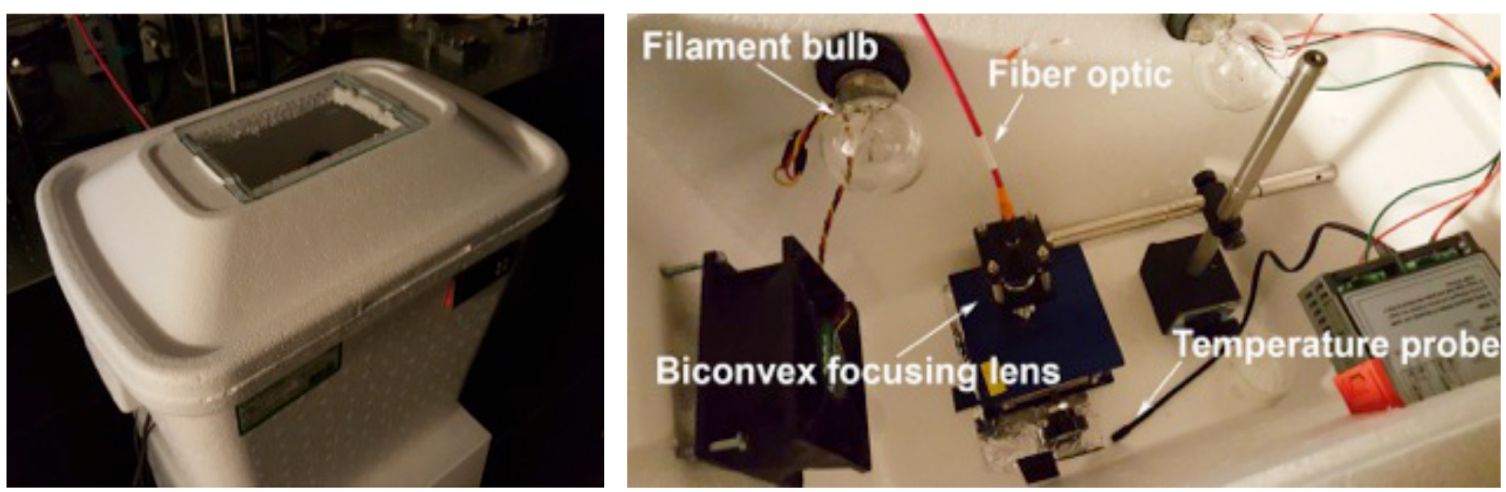

Figure SI Incubator used for in vitro photothermal studies.

Notes: The heat in the incubator was generated using filament bulbs that were wired to an STC-1000 probe temperature controller. The temperature controller maintained a constant temperature of $37^{\circ} \mathrm{C} \pm 1{ }^{\circ} \mathrm{C}$ within the incubator. The $\mathrm{CO}_{2}$ level within the incubator was not maintained.

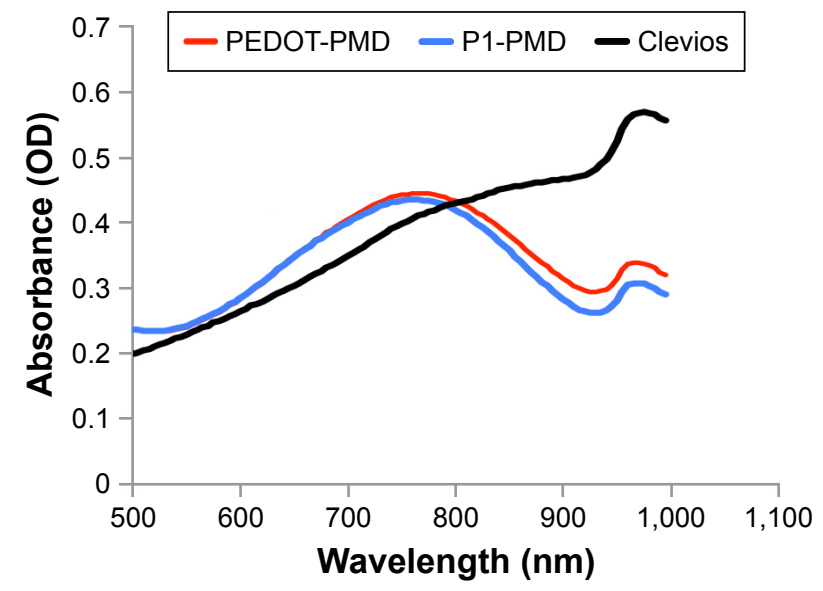

Figure S2 Absorption spectra of PI-PDM, PEDOT-PMD, and Clevios PHI000 nanoparticles.

Note: PI-PMD and PEDOT-PMD exhibit absorption peaks in the near infrared range, while Clevios $\mathrm{PHI} 000$ has a broad absorption band.

Abbreviations: OD, optical density; PI, poly(diethyl-4,4'-\{[2,5-bis(2,3-dihydrothieno[3,4-b][1,4]dioxin-5-yl)-1,4-phenylene]bis(oxy)\} dibutanoate); PEDOT, poly (3,4-ethylenedioxythiophene); DBSA, 4-dodecylbenzenesulfonic acid; PSS-co-MA, poly(4-styrenesulfonic acid-co-maleic acid); PI-PMD, PI:PSS-co-MA:DBSA; PEDOTPMD, PEDOT:PSS-CO-MA:DBSA.

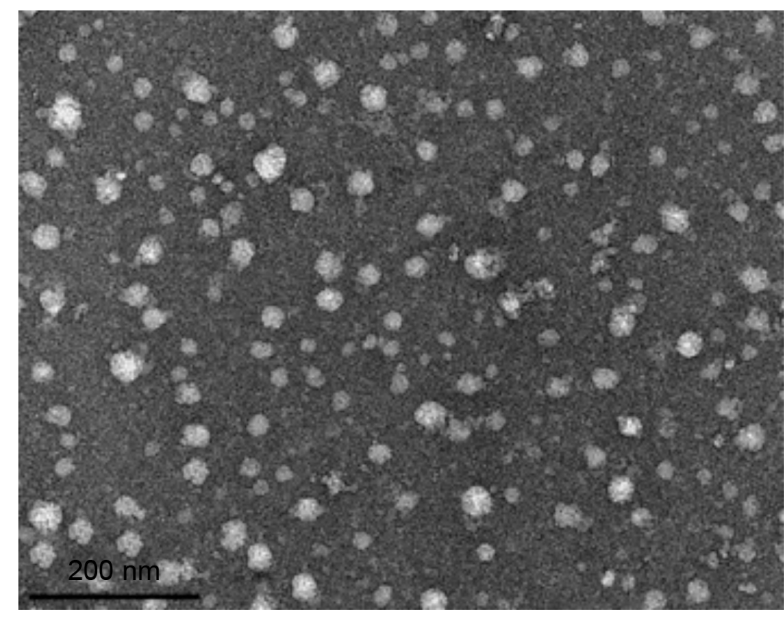

Figure S3 TEM image of PI-PMD NPs that were irradiated with 808-nm laser at a power density of $2 \mathrm{~W} / \mathrm{cm}^{2}$ for $30 \mathrm{~min}$.

Note: No differences are observed in the morphology or size of the NPs after irradiation.

Abbreviations: NPs, nanoparticles; PI, poly(diethyl-4,4'-\{[2,5-bis(2,3-dihydrothieno[3,4-b][1,4]dioxin-5-yl)-I,4-phenylene]bis(oxy)\} dibutanoate); DBSA, 4-dodecylbenzenesulfonic acid; PSS-co-MA, poly(4-styrenesulfonic acid-co-maleic acid); PI-PMD, PI:PSS-co-MA:DBSA;TEM, transmission electron microscopy. 

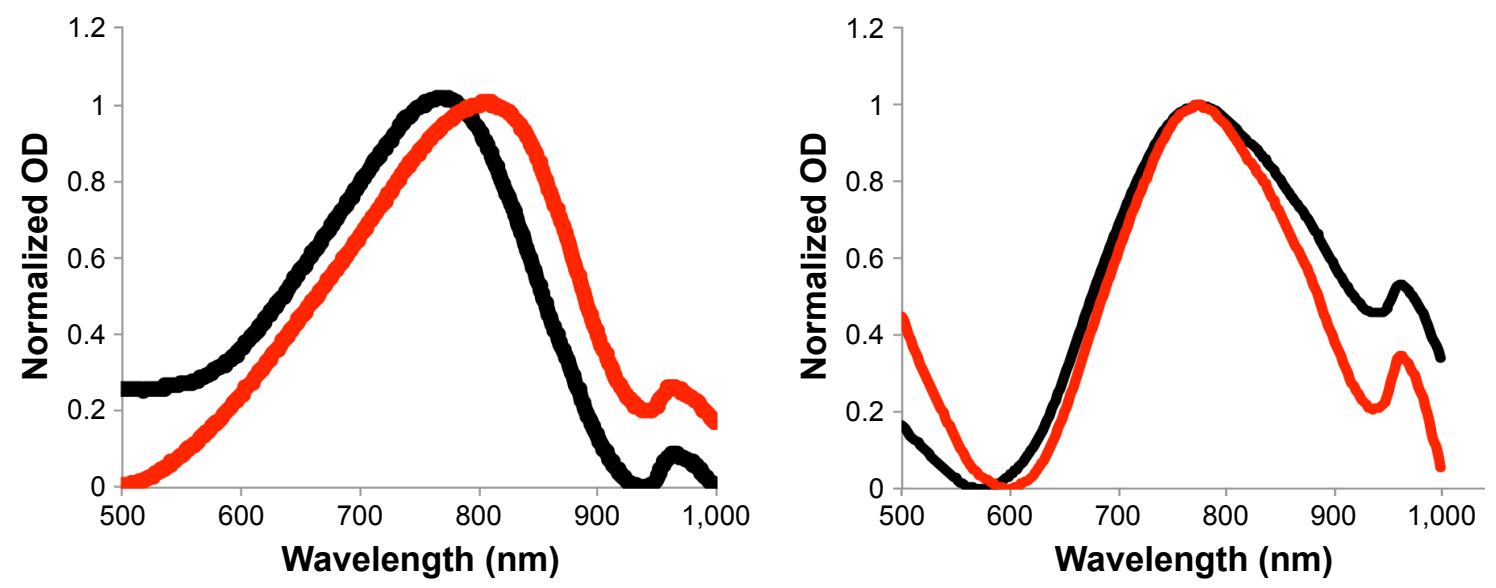

NPs in water NPs in media

Figure S4 Absorption spectra of PI-PMD (left) and PEDOT-PMD (right) nanoparticles in water and complete cell media demonstrating that the peak absorption of these NPs does not blueshift in the presence of salts or serum.

Note: A shift to lower wavelengths would decrease their effectiveness as agents for photothermal therapy.

Abbreviations: NPs, nanoparticles; OD, optical density; PI, poly(diethyl-4,4'-\{[2,5-bis(2,3-dihydrothieno[3,4-b][I,4]dioxin-5-yl)-I,4-phenylene]bis(oxy)\} dibutanoate); PEDOT, poly(3,4-ethylenedioxythiophene); DBSA, 4-dodecylbenzenesulfonic acid; PSS-co-MA, poly(4-styrenesulfonic acid-co-maleic acid); PI-PMD, PI:PSS-co-MA:DBSA; PEDOT-PMD, PEDOT:PSS-co-MA:DBSA.
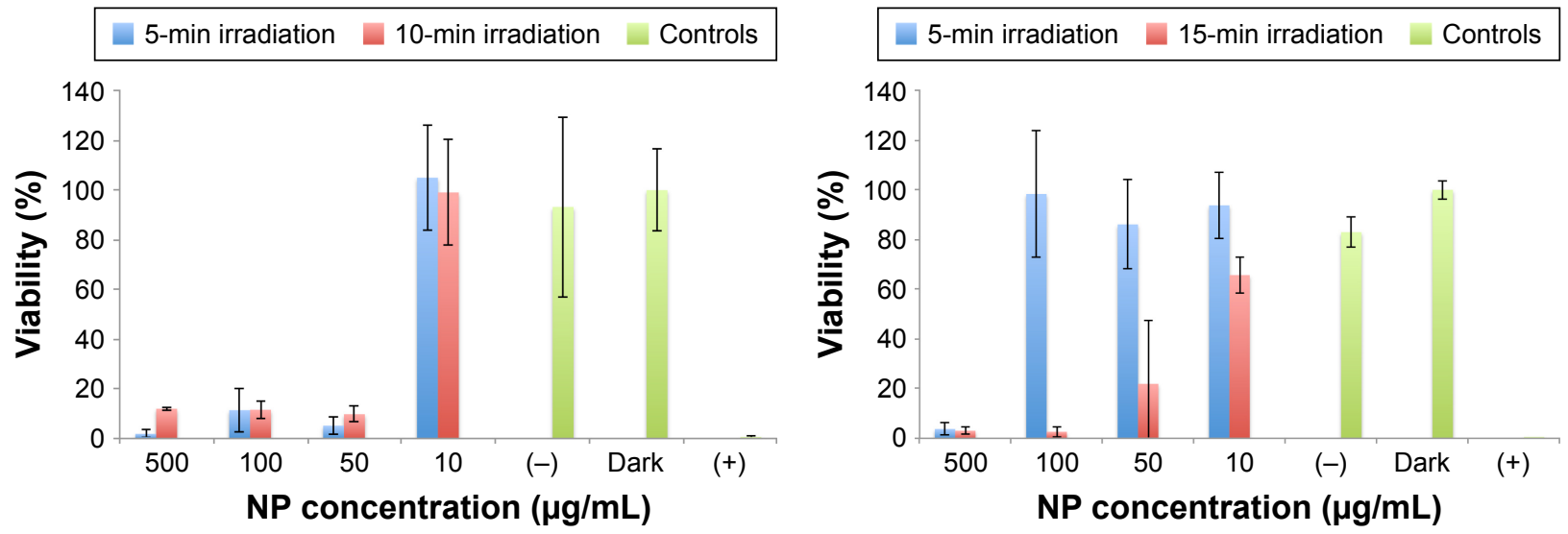

Figure S5 Percent viability of MDA-MB-23I breast cancer cells upon photothermal ablation. Viability was determined by quantitation of green (calcein acetoxymethyl) fluorescence intensity from the images of live/dead assay. Data provided as a percentage of the fluorescence of the dark control. Left: PI-PMD NPs. Right: PEDOT-PMD NPs. Controls: (-) Negative control = cells irradiated for 15 min, but not exposed to NPs; Dark control cells exposed to NPs, but not irradiated; (+) Positive control = cells killed with methanol. Error bars represent the standard deviation between the mean values of the green fluorescence of the cells in independent pictures of the same condition. Abbreviations: NP, nanoparticle; PI, poly(diethyl-4,4'-\{[2,5-bis(2,3-dihydrothieno[3,4-b][I,4]dioxin-5-yl)-I,4-phenylene]bis(oxy)\} dibutanoate); PEDOT, poly(3,4ethylenedioxythiophene); DBSA, 4-dodecylbenzenesulfonic acid; PSS-co-MA, poly(4-styrenesulfonic acid-co-maleic acid); PI-PMD, PI:PSS-co-MA:DBSA; PEDOT-PMD, PEDOT:PSS-CO-MA:DBSA. 


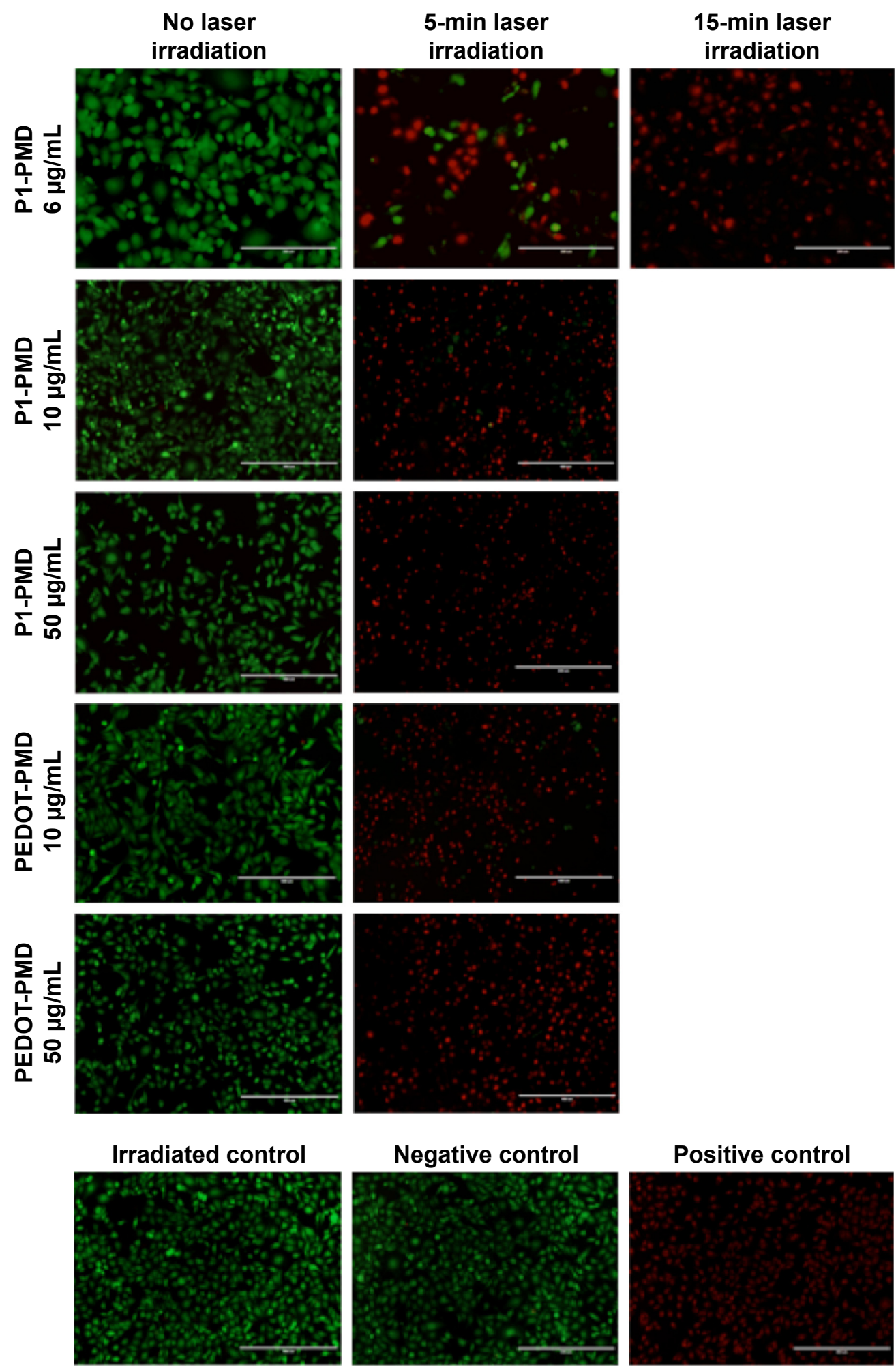

Figure S6 Live/dead assay of MDA-M-23I cells exposed to PI-PMD or PEDOT-PMD NPs at various concentrations and irradiated with an $808-\mathrm{nm}$ laser at $7 \mathrm{~W} / \mathrm{cm}^{2}$ in the presence of the NPs.

Notes: Images are overlays of both green and red channels. Negative control consists of cells irradiated for $15 \mathrm{~min}$ in the absence of NPs. Dark control consists of cells that were neither irradiated nor exposed to NPs. Scale bars represent $200 \mu \mathrm{m}$ for concentrations of $6 \mu \mathrm{m} / \mathrm{mL}$ of PI-PMD and $400 \mu \mathrm{m}$ for concentrations of 10 and $50 \mu g / \mathrm{mL}$ for both PI-PMD and PEDOT-PMD.

Abbreviations: NPs, nanoparticles; PI, poly(diethyl-4,4'-\{[2,5-bis(2,3-dihydrothieno[3,4-b][1,4]dioxin-5-yl)-1,4-phenylene]bis(oxy)\} dibutanoate); PEDOT, poly(3, 4-ethylenedioxythiophene); DBSA, 4-dodecylbenzenesulfonic acid; PSS-co-MA, poly(4-styrenesulfonic acid-co-maleic acid); PI-PMD, PI:PSS-co-MA:DBSA; PEDOT-PMD, PEDOT:PSS-co-MA:DBSA. 

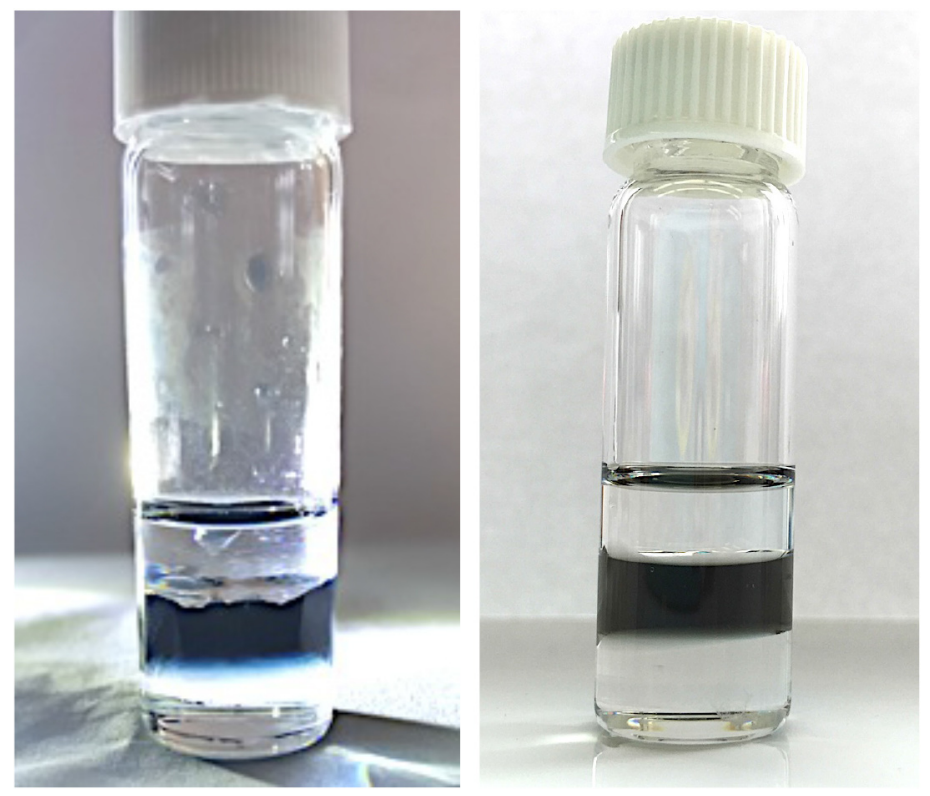

Figure S7 Images of PI-PMD (left) and PEDOT-PMD (right) NP aqueous suspensions layered between chloroform (bottom) and toluene (top). NPs are well stabilized in aqueous suspension.

Abbreviations: NP, nanoparticle; PI, poly(diethyl-4,4'-\{[2,5-bis(2,3-dihydrothieno[3,4-b][I,4]dioxin-5-yl)-I,4-phenylene]bis(oxy)\} dibutanoate); PEDOT, poly(3,4ethylenedioxythiophene); DBSA, 4-dodecylbenzenesulfonic acid; PSS-co-MA, poly(4-styrenesulfonic acid-co-maleic acid); PI-PMD, PI:PSS-co-MA:DBSA; PEDOT-PMD, PEDOT:PSS-CO-MA:DBSA.

\section{Publish your work in this journal}

The International Journal of Nanomedicine is an international, peerreviewed journal focusing on the application of nanotechnology in diagnostics, therapeutics, and drug delivery systems throughout the biomedical field. This journal is indexed on PubMed Central, MedLine, CAS, SciSearch $®$, Current Contents ${ }^{\circledR} /$ Clinical Medicine,
Journal Citation Reports/Science Edition, EMBase, Scopus and the Elsevier Bibliographic databases. The manuscript management system is completely online and includes a very quick and fair peer-review system, which is all easy to use. Visit http://www.dovepress.com/ testimonials.php to read real quotes from published authors. 